\title{
A gestão de pessoas como um recurso estratégico*
}

ONU/Departamento de Assuntos Econômicos e Sociais

\section{Adotando uma abordagem holística às reformas}

Que medidas os governos deveriam adotar para melhor gerir seus servidores? Este trabalho discute alguns dos elementos-chave da abordagem estratégica às reformas da gestão de recursos humanos (GRH) no setor público. Recomenda que os governos desenvolvam uma estratégia de GRH fundamentada nos melhores atributos de três escolas ou modelos de administração pública: a administração pública tradicional; a gestão pública, incluindo a Nova Gestão Pública (NGP); e a governança responsiva. Cada um desses três modelos apresenta pontos fortes e destaca os valores essenciais para fazer frente aos desafios contemporâneos de GRH no setor público.

É interessante notar que alguns dos pioneiros e mais entusiasmados defensores do modelo NGP, como a Austrália e a Nova Zelândia, redescobriram, em anos recentes, as virtudes da administração pública tradicional, em especial, o valor dos princípios da imparcialidade e do mérito. O modelo da gestão pública 
também tem contribuído com importantes princípios, ferramentas e técnicas para a reforma da GRH, particularmente na área do desempenho e da gestão por resultados. Recentemente, o paradigma da governança trouxe à tona novas abordagens e conceitos para tornar a administração pública mais responsiva às demandas dos cidadãos e de outros stakeholders. Cada modelo, nesse sentido, oferece atributos importantes para melhorar a GRH no setor público. Os princípios unificadores dessa síntese da GRH seriam a imparcialidade, o profissionalismo e a responsividade.

Como ponto de partida para o desenvolvimento de um quadro sintético da GRH para o serviço público foram identificados os seguintes componentes:

- um serviço público politicamente imparcial, profissional e baseado no mérito;

- a existência de um órgão "guardião" central, que exerça liderança estratégica e monitore um sistema de gestão descentralizado no lugar de operar por meio de controles burocráticos;

- forte foco na gestão por resultados por meio do uso de padrões de desempenho e indicadores efetivos, assim como critérios de promoção que confiram maior peso à eficiência relativa (em detrimento da antigüidade);

- a existência de regras duras e objetivas e de órgãos de combate à corrupção;

- disposições legais e normas profissionais que facilitem o controle/escrutínio externo do serviço público; e

- conjuntos de sistemas e competências que garantam um alto nível de capacidade de comunicação por meio da formação de redes, articuladas pelo emprego eficiente da tecnologia da informação.

Os componentes mencionados servem para ilustrar como os governos podem desenvolver um parâmetro de
GRH que atenda a suas necessidades específicas e prioridades para aumentar as competências dos servidores no sentido de contribuir para a consecução dos objetivos nacionais de desenvolvimento. O parâmetro é um ponto de partida, um instrumento que serve de base de comparação para os governos, e não um plano traçado. Reformas raramente acontecem no atacado, baseadas em projetos formatados e da noite para o dia e, se assim fossem, seriam provavelmente indesejáveis.

A tabela 1 destaca algumas das características da GRH dos três modelos de administração pública. Este trabalho defende que os países em desenvolvimento devem priorizar a implementação de um serviço público baseado em carreiras que funcione bem, para depois abraçar uma reforma institucional e legal mais complexa. Existem, todavia, muitas possibilidades de revitalização da gestão do serviço público por meio da introdução seletiva de características dos modelos da gestão pública e da governança responsiva na administração pública tradicional.

Governos que tenham adotado o sistema de administração pública tradicional, por exemplo, podem torná-lo mais responsivo, adotando medidas de reforma como: submeter funcionários seniores à accountability 360 graus; fortalecer a mensuração do desempenho e a sua comunicação; introduzir o aprendizado organizacional no serviço público; focar em valores que promovam a prestação de serviços centrada no cidadão; e fortalecer as relações entre o exercício da atividade pública e a gestão. Tais medidas, incrementais, porém estratégicas, podem sem dúvida fazer a diferença no aumento do nível de responsividade do serviço público aos seus vários stakeholders na sociedade, 
Tabela 1: Características da GRH selecionadas a partir dos três modelos de administração pública

\begin{tabular}{|c|c|c|c|}
\hline & $\begin{array}{l}\text { Administração pública } \\
\text { tradicional }\end{array}$ & Gestão pública & $\begin{array}{l}\text { Governança } \\
\text { responsiva }\end{array}$ \\
\hline \multirow[t]{3}{*}{$\begin{array}{l}\text { Sistema do serviço } \\
\text { público }\end{array}$} & Fechado e delimitado & $\begin{array}{l}\text { Aberto e descen- } \\
\text { tralizado }\end{array}$ & Aberto e regulado \\
\hline & $\begin{array}{l}\text { Serviço público de } \\
\text { carreira }\end{array}$ & $\begin{array}{l}\text { Sistema baseado } \\
\text { em postos }\end{array}$ & $\begin{array}{l}\text { Carreiras-base no } \\
\text { serviço público; } \\
\text { outros cargos } \\
\text { baseados em postos }\end{array}$ \\
\hline & Estabilidade & Prazo definido & $\begin{array}{l}\text { Estabilidade e prazo } \\
\text { definido }\end{array}$ \\
\hline \multirow[t]{3}{*}{ Arranjos institucionais } & $\begin{array}{l}\text { Autoridade central de } \\
\text { recursos humanos in- } \\
\text { dependente }\end{array}$ & $\begin{array}{l}\text { GRH descentralizada } \\
\text { para ministérios de li- } \\
\text { nha de frente }\end{array}$ & $\begin{array}{l}\text { Regulador-líder } \\
\text { de GRH; GRH } \\
\text { descentralizada }\end{array}$ \\
\hline & $\begin{array}{l}\text { Administração de } \\
\text { pessoal }\end{array}$ & $\begin{array}{l}\text { Gestão de recursos hu- } \\
\text { manos }\end{array}$ & $\begin{array}{l}\text { GRH estratégica e } \\
\text { desenvolvimento }\end{array}$ \\
\hline & $\begin{array}{l}\text { Sistema de salários } \\
\text { unificado }\end{array}$ & Contratos individuais & $\begin{array}{l}\text { Sistema de salários } \\
\text { unificado e por } \\
\text { desempenho }\end{array}$ \\
\hline Progressão na carreira & $\begin{array}{l}\text { Baseado na } \\
\text { antigüidade }\end{array}$ & $\begin{array}{l}\text { Baseado no } \\
\text { desempenho }\end{array}$ & $\begin{array}{l}\text { Escala de } \\
\text { competências }\end{array}$ \\
\hline Política de salário & $\begin{array}{l}\text { Baseado na } \\
\text { experiência e nas } \\
\text { qualificações }\end{array}$ & $\begin{array}{l}\text { Critérios baseados } \\
\text { no trabalho com } \\
\text { elementos de } \\
\text { desempenho }\end{array}$ & $\begin{array}{l}\text { Critérios baseados } \\
\text { no trabalho com } \\
\text { elementos de } \\
\text { desempenho }\end{array}$ \\
\hline $\begin{array}{l}\text { Gestão por } \\
\text { desempenho }\end{array}$ & Ética profissional & Acordo de desempenho & Accountability $360^{\circ}$ \\
\hline $\begin{array}{l}\text { Desenvolvimento de } \\
\text { recursos humanos }\end{array}$ & $\begin{array}{l}\text { Habilidades } \\
\text { funcionais }\end{array}$ & Competências & $\begin{array}{l}\text { Competências e } \\
\text { habilidades relacionais }\end{array}$ \\
\hline
\end{tabular}

sem minar os dogmas da administração pública tradicional.

Da mesma forma, os governos podem elevar o profissionalismo do serviço público ao introduzir algumas das melhores características do modelo da gestão pública na administração tradicional. Isso pode incluir maior ênfase na profissionalização da GRH, bem como sua integração com processos estratégicos de planejamento organizacional no serviço público; reestruturação da política de salários, vinculando-a às condições do mercado de trabalho; introdução de processos de seleção e treinamento de servidores centrados em competências; e estabelecimento de padrões para qualidade do serviço no setor público.

Quais sejam os componentes que os governos identifiquem como prioridades para seus respectivos parâmetros de GRH, eles devem procurar adotar uma abordagem holística e gradual às reformas de GRH no setor público. O ideal seria 
que os governos trabalhassem cada um dos itens de um quadro global seguindo uma ordem lógica. No entanto, tendo em mente a noção de "começar de onde você está", um governo pode, por exemplo, optar por começar pela gestão por desempenho como forma de conscientizar seus gerentes, pela primeira vez, de que eles são responsáveis pelo desempenho de sua equipe, como foi feito em Marrocos; ou pela redução de empregos por conta da necessidade predominante de compatibilizar os gastos com pessoal e as receitas do governo, como Camboja, muitos outros países em desenvolvimento e economias de transição fizeram-no; ou por qualquer questão de recursos humanos que seja prioridade no momento.

\section{Construindo um quadro institu- cional eficiente de GRH}

\section{Reforma legal e regulatória}

Tradicionalmente, o principal objetivo das leis e normas que regem os servidores públicos tem sido o de protegê-los de interferências políticas, étnicas, religiosas e fiscais, bem como o de proteger o público de administrações e prestação de serviços arbitrárias ou mesmo enviesadas. Além de estipular quais funções devem receber o status de serviço público (uma questão sempre controversa), as leis e normas definem o papel do serviço público na gestão de assuntos públicos, os valores e princípios que devem nortear servidores públicos no exercício de suas funções, bem como seus direitos e obrigações.

Algumas das mais abrangentes reformas do marco legal no setor público em anos recentes ocorreram em países do antigo bloco oriental. $\mathrm{Na}$ era soviética, os servidores públicos nesses países estavam sujeitos a leis trabalhistas comuns. $\mathrm{O}$ desmantelamento do bloco oriental, no entanto, provocou grandes reformas administrativas e no serviço público. Inicialmente, os serviços públicos foram reorganizados com base em modelos empregatícios do direito privado, para, no final dos anos 90 e no início do novo século, serem adotados mecanismos estatutários (Council of Europe, 2003). Este último desdobramento, em especial, foi facilitado pela perspectiva de incorporação dos países do antigo bloco oriental à União Européia.

Ao mesmo tempo, muitos países em desenvolvimento optaram por restringir o status de servidor público a órgãos centrais do governo, enquanto passavam a recorrer a arranjos empregatícios mais flexíveis para gerir, por exemplo, professores no setor educacional. Contudo, em países desenvolvidos, os horizontes dos estatutos são freqüentemente estabelecidos por longos períodos. Assim, com a continuidade assegurada, o principal objetivo da reforma tem sido, geralmente, introduzir maior flexibilidade no "como" os objetivos das políticas são alcançados. Em alguns casos, isso levou ao maior uso de contratos de trabalho por tempo determinado no serviço público, em especial para "recalibrar" as competências de servidores em setores prioritários, tornando a força de trabalho do setor público mais responsiva às necessidades dos cidadãos.

Seja para criar ou alterar a legislação que rege o emprego no serviço público, é essencial incutir o princípio do mérito. Embora várias forças se combinem para assegurar ou equilibrar o mérito com outros valores como a diversidade e a representação, a definição e a aplicação tradicional do mérito ainda é válida. Em muitos casos, porém, precisa ser modernizada. O desenvolvimento de uma 
definição moderna do que constitui um serviço público de carreira baseado no mérito deve ser prioridade em muitos países em desenvolvimento.

O Código de Modernização do Serviço Público de 2003, no Canadá, é um exemplo de como o mérito pode ser determinado por lei. Antes, o mérito no serviço público canadense era definido pela jurisprudência e pelos costumes, o que resultou em um regime de nomeação motivado por processos. Historicamente, mérito significava selecionar a pessoa mais bem qualificada entre os candidatos. Isso mudou com o Código do Trabalho no Serviço Público, de 1992, pelo qual a noção de mérito foi ampliada passando a incluir também a mensuração das qualificações de acordo com um conjunto de padrões. As mudanças recentes trazidas pelo Código de 2003 estão descritas no Quadro 1.

A promoção da integridade é de igual importância no serviço público. Não é difícil identificar arranjos institucionais que promovem com maior sucesso a integridade e o combate à corrupção. Primeiro, deve haver um conjunto coerente de leis com disposições penais, civis e administrativas que punam a corrupção no serviço público. Essas disposições devem ser claras e impor penalidades suficientes para coibir e vigorar com eficiência. No caso de corrupção na burocracia, devem incluir tanto um conjunto de medidas disciplinares que, entre outros, possa resultar em demissão e perda dos direitos à aposentadoria como unidades administrativas designadas para levar adiante tais medidas. Em segundo lugar, regras e procedimentos administrativos devem ser claros e transparentes de maneira a informar os cidadãos sobre seus direitos, responsabilidades e padrões de serviços. Essa transparência, somada à accountability dos servidores públicos em relação a seus desempenhos, favorece o comprometimento entre o cidadão e o exercício da função pública e serve como medida efetiva para promover o profissionalismo e inibir a corrupção. Para facilitar o feedback do público, deve-se também disponibilizar canais públicos para reclamações e reparações.

Em resumo, um marco legal claro é alicerce indispensável para a GRH no setor

"Os princípios

subjacentes a um

serviço público

imparcial,

profissional e

responsivo devem ser

protegidos por um

órgão guardião, que

tenba prestígio $e$

poder no centro do

governo para

promover e replicar

um conjunto de

valores e

comportamentos."

público. O marco deve garantir a continuidade na gestão de pessoas e, ao mesmo tempo, assegurar a flexibilidade adequada ao governo no poder para modernizar a aplicação de princípios e conceitos-chave, conforme as demandas de um setor público em desenvolvimento. No momento de esboçar a legislação, os governos devem dedicar atenção, pelo menos, às seguintes questões-chave (WORD BANK, 1997): 


\section{Quadro 1: O Código de Modernização do Serviço Público - Canadá}

Os princípios de não-partidarismo e mérito sempre foram fundamentais para o serviço público canadense. O mérito é a base para todas as nomeações no serviço público. Contudo, o termo nunca fora previsto em legislação e era, portanto, basicamente definido pela jurisprudência e pelos costumes. Essa ausência de definição do que constitui o mérito resultou em um regime de nomeações confuso e baseado em processos, o qual inibiu a habilidade do serviço público de contratar e promover funcionários de forma eficiente.

O serviço público no Canadá, como em outros países, enfrenta diversos desafios em relação à GRH, que incluem um mercado de trabalho cada vez mais competitivo; mudanças demográficas tanto em termos de idade quanto de representação; crescente necessidade de investimento em desenvolvimento de pessoal para melhorar as relações entre a execução das atividades e a gestão e afinar os mecanismos de accountability; e gradual deterioração da imagem do emprego no serviço público, o que dificulta, para os gerentes, contratar e reter talentos.

Fazendo frente a esse cenário, o Parlamento do Canadá adotou, em novembro de 2003, o Código de Modernização do Serviço Público (PSMA - Public Service Modernization $A(t)$. O código, que entrará em pleno vigor no segundo semestre de 2005, trará as maiores mudanças em GRH dos últimos 35 anos. Ele consiste de quatro leis principais: a Lei do Emprego no Serviço Público, a Lei das Relações Trabalhistas no Serviço Público, Emendas à Lei de Administração Financeira; e Emendas à Lei do Centro Canadense de Desenvolvimento da Gestão. O novo Código também institui a Agência de Gestão de Recursos Humanos do Serviço Público do Canadá, responsável pela implementação da agenda de reforma da GRH.

O Código de Modernização do Serviço Público visa atingir quatro principais objetivos:

- tornar o regime de seleção mais flexível para facilitar a contratação das pessoas certas quando e onde necessário com as devidas salvaguardas;

- possibilitar maior colaboração na relação entre o exercício da atividade e a gestão;

- promover aprendizado e treinamento mais focado e integrado para servidores de todos os níveis; e

- definir mais claramente os papéis e responsabilidades da Secretaria do Conselho do Tesouro, da Comissão do Serviço Público, dos chefes executivos e seus gerentes.

O Código de Modernização do Serviço Público procura reforçar salvaguardas para manter um serviço público baseado em mérito e não partidário, fundamentado nos valores da transparência, justiça e respeito. Chefes executivos continuarão sendo aptos a estabelecer as metas de qualidade para o trabalho a ser realizado em suas respectivas organizações, e, entrando o código em pleno vigor, os gerentes terão mais flexibilidade na área de recrutamento. O código também estabelece um Tribunal de Servidores do Serviço Público para a resolução de contenciosos entre a equipe e a gerência. A Comissão do Serviço Público continuará a exercer um papel crítico na proteção da integridade dos processos de contratação em todo o governo. O código também exige que departamentos estabeleçam comitês de consulta entre os níveis operacional e de gerência como um fórum para diálogo de questões de interesse mútuo. Além disso, promoverá aprendizado e desenvolvimento de carreira 
contínuos. A Escola Canadense de Serviço Público (Canada School of Public Service) será aberta e acessível aos servidores de todos os níveis nos departamentos, agências e regiões.

O governo do Canadá foi capaz de promover uma reforma tão abrangente em razão do grande apoio de líderes administrativos e políticos e outros stakeholders-chave. Havia consenso sobre a necessidade de fortalecimento significativo da GRH no serviço público, o que tornou politicamente viável a adoção do projeto de lei. Como resultado, estabeleceu-se um caloroso debate parlamentar sobre o projeto de lei e líderes sindicais, acadêmicos, bem como antigos e atuais executivos do serviço público ofereceram seus conhecimentos e especialidades nas audiências do comitê. O processo preparatório também envolveu extensivas consultas com servidores públicos.

- Qual é a opção possível de política preferida?

- Essa opção deve ser concretizada por meios legislativos ou não-legislativos?

- Quais autoridades devem implementar a legislação?

- Qual é a abordagem básica a ser adotada na legislação?

- Que mecanismos legais e administrativos são necessários para pôr em prática essa abordagem e torná-la funcional?

Por conta do papel estratégico dos servidores públicos na manutenção das instituições estatais ao longo do tempo, a proteção - estatutária ou de algum outro tipo - faz-se necessária, especialmente em países em desenvolvimento. Em um serviço público imparcial, profissional e responsivo, os servidores nomeados também devem ser subordinados aos políticos eleitos pelo povo. Ao mesmo tempo, é apropriado distinguir a esfera política da administrativa. De maneira geral, os políticos deveriam "guiar, e não censurar": definir o quadro das políticas, estabelecer metas quando necessárias, mas depois deixar que os servidores realizem o trabalho de implementar a política e cumprir as metas de maneira profissional e responsiva. Por sua parte, os servidores devem implementar as políticas fidedignamente, dentro do razoável, e não procurar criar uma base de poder rival.
É necessário, também, fazer a devida previsão das instituições básicas na constituição nacional e alterá-la quando elas se provarem inadequadas. A experiência ocorrida em Sri Lanka exemplifica isso. Em 1972, o governo aboliu a independência da Comissão do Serviço Público, órgão responsável pela contratação no serviço público, subordinando-a ao gabinete, em uma tentativa de tornar os servidores menos distantes dos cidadãos e mais sensíveis aos objetivos de desenvolvimento. No entanto, isso levou à politização da nomeação pública e à deterioração na qualidade do serviço. Em 2001, em um marcante exercício de renúncia, todos os principais partidos uniram-se para apoiar uma emenda constitucional que reinstituía a independência da Comissão do Serviço Público. Eles também concordaram em nomear membros da comissão que tornassem essa independência uma realidade, mesmo que isso significasse enfrentar interesses políticos.

\section{Governo central: conferindo papel de liderança à GRH}

Quando os governos discutem sobre quem deve ser o responsável pela gestão de recursos humanos, o debate incide geralmente sobre a parcela de autoridade que o órgão ou departamento central deve 
deter em relação aos seus órgãos e departamentos da linha de frente. Cabe aos governos também, no entanto, decidir sobre a divisão apropriada de responsabilidade entre eles. Os papéis atribuídos aos respectivos ministérios, nos diversos países em que a responsabilidade pela GRH não foi delegada a ministérios e órgãos da linha de frente, são, de maneira geral, similares aos apresentados na tabela 2.

Essa estrutura é particularmente parecida com a do modelo da Commonwealth, especialmente no que diz respeito ao papel atribuído à Comissão do Serviço Público (CSC), mas até países não participantes da Commonwealth, como a República da Coréia e a Tailândia, têm arranjos similares. As Comissões do Serviço Público são freqüentemente associadas ao modelo Westminster, enquanto na maioria dos países francófonos as responsabilidades da comissão são geralmente delegadas a cada um dos ministérios, aproximando-se do sistema mixto francês.

Um importante elemento omitido por essa versão idealizada é a organização de servidores públicos, em muitos países, em "cadres" (quadros) ou "corps" (corpos), cada qual vinculado a um ministério de origem. Em sua maior parte, os quadros guardam, até certo ponto, bastante correspondência aos respectivos ministérios. Assim, a maioria dos membros do quadro de pessoal da educação trabalha em escolas, sob a autoridade do Ministério da Educação. No entanto, membros de quadros administrativos e gerenciais podem ser lotados em qualquer ministério, ainda que a promoção e a transferência sejam nominalmente controladas pelo Ministério do Serviço Público. Isso gera potencial para conflitos entre o ministério de origem e o ministério no qual o gestor efetivamente trabalha.

É fácil verificar como essa estrutura pode levar, sob um ponto de vista estratégico, à fragmentação da GRH e ser fonte de conflitos entre diferentes órgãos. $\mathrm{Na}$ era do ajuste estrutural, quando muitos governos tentavam reduzir o número de servidores, os ministérios do Serviço Público eram freqüentemente considerados pelos ministérios econômicos como um cavalo de Tróia dentro do governo, atuando como um sindicato informal para frustrar os objetivos da reforma (Corkery; LAND, 1997). Os servidores no Ministério da Fazenda em Gana, por exemplo, não escondiam sua visão de que seus colegas do Ministério do Serviço Público eram a maior ameaça ao sucesso da reforma (McCourt, 2001).

Do ponto de vista de uma GRH estratégica, a solução, novamente, pode parecer

\section{Tabela 2: A responsabilidade pela GRH em órgãos do governo central}

\begin{tabular}{l|l}
\hline Órgão & Função \\
\hline Gabinete do primeiro-ministro & Políticas governamentais em geral \\
\hline Ministério da Fazenda & Salários e pensões \\
\hline Ministério do Serviço Público & $\begin{array}{l}\text { Desenvolvimento de carreiras e condições de } \\
\text { trabalho para servidores públicos }\end{array}$ \\
\hline Comissão do Serviço Público & Nomeação, promoção, transferência e disciplina \\
\hline Escolas nacionais de governo & Treinamento e desenvolvimento \\
\hline
\end{tabular}


simples: reunir todas as funções em um único órgão estratégico, possivelmente o gabinete do primeiro-ministro ou seu similar. Alguns governos seguiram nessa direção. Essa foi parte da razão pela qual o Reino Unido aboliu o Departamento do Serviço Civil em 1979 e transferiu suas responsabilidades para o Gabinete. Governo algum, todavia, levou a cabo esse argumento, especialmente porque os ministérios da Fazenda por toda parte são relutantes em abrir mão de seu poder sobre o pagamento dos servidores públicos, que consomem grande parcela do gasto público.

O caráter path-dependent da administração pública é outra razão pela qual órgãos bem estruturados e com tradição de competência, como as escolas nacionais de governo, conseguem manter-se em posição central, muito embora sua própria existência enfraqueça o impulso estratégico do governo.

A lição universal é que os princípios subjacentes a um serviço público imparcial, profissional e responsivo precisam ser institucionalizados, publicizados e protegidos por um órgão (ou conjunto de órgãos) guardião, que tenha prestígio e poder no centro do governo. Tal órgão deve promover e replicar um conjunto de valores e comportamentos por meio de orientações e aconselhamento sobre a política de emprego no serviço público, desenvolver códigos de ética e exercer vigilância especial sobre o recrutamento, a promoção e a avaliação de desempenho de servidores públicos, bem como sobre o planejamento de carreira para os níveis de direção do núcleo do serviço público.

O órgão líder para assumir a GRH seria, normalmente, o gabinete do primeiro-ministro e, em alguns casos, o Ministério do Serviço Público ou seu equivalente. Esse órgão coordenador precisaria ter estrutura adequada para oferecer consultoria a outros órgãos centrais - e possivelmente outros ministérios - para desenvolver uma política de GRH. O Ministério do Serviço Público no Marrocos realizou recentemente algumas mesas-redondas, reunindo representantes de diversoss órgãos. Essa iniciativa é um primeiro passo bastante útil para o estabelecimento de uma estrutura mais regular de coordenação.

Órgãos centrais e de linha de frente: estabelecendo a divisão de responsabilidades sobre a GRH

Delegar responsabilidade de gestão a órgãos da linha de frente é parte central da fórmula da Nova Gestão Pública (NGP) para gerir o serviço público, prática presente em muitos países industrializados. No serviço público do Reino Unido, por exemplo, a delegação tem sido um processo gradual iniciado em 1964, quando a contratação de servidores para serviços de escritório foi transferida aos departamentos. A Comissão do Serviço Público continuava a aprovar as nomeações, mas a necessidade de aprovação foi abolida em 1983. Em 1991, todo o recrutamento de servidores de carreiras abaixo do grau 7 (nível gerencial médio) também foi delegado, e em 1995, o ponto de corte foi elevado para os de grau 5 (nível gerencial sênior).

Além disso, a esfera central passou, progressivamente, a delegar o poder sobre salários e escalas aos departamentos. Atualmente, o papel da Comissão do Serviço Público do Reino Unido é meramente de editar padrões de conduta, fazer nomeações até o carreiras de grau 5, julgar recursos administrativos, realizar auditorias em seleções e promover boas práticas nos departamentos por meio do estabelecimento de diretrizes para 
processos seletivos. Nos órgãos de linha de frente do Reino Unido, os gerentes são responsáveis pela seleção, disciplina, gratificações por desempenho e desenvolvimento de carreiras. As unidades de GRH são particularmente úteis como colaboradoras na elaboração de estratégias e políticas de pessoal dos departamentos e como provedoras de serviços de apoio para os gerentes de linha. Essas unidades são responsáveis por salários e classificação de carreiras abaixo do grau 5, planejamento de transições, auditoria e monitoramento do desempenho e fornecimento, a gerentes, de assessoria em seleção, disciplina e treinamento, quando necessário. Assim, após um quarto de século de delegação gradual de responsabilidade, a idéia de um serviço público uniforme e administrado centralmente está chegando ao fim no Reino Unido. É a pressão profissional dos colegas e não os controles centrais que mantêm a integridade do processo de recrutamento dos servidores públicos.

A delegação da responsabilidade pode ser apropriada, porém, apenas em países que a implementam gradualmente e nos quais o mecanismo de pressão profissional pode operar. Em países nos quais controlar o nepotismo e o favoritismo é uma prioridade, a melhoria da qualidade e responsividade do recrutamento é tratada mais efetivamente com uma estrutura de seleção central. De fato, em países nos quais o respeito pelo Estado de direito e a cultura de transparência não estão internalizados e, ao contrário, o nepotismo e o favoritismo são amplamente disseminados, o efetivo controle central pode ser a única opção viável.

Cada vez mais, à medida que os governos começaram a questionar o valor do modelo NGP, vem reconhecendo-se que processos muito rápidos de descentralização das funções de GRH podem levar a um declínio no profissionalismo do serviço público. A redução do papel das agências centrais de pessoal, que tinham responsabilidades por todo o serviço, também significou que alguns sistemas de apoio significativos para a manutenção do ethos do serviço público foram negligenciados.

Mais recentemente, a ênfase na desregulamentação das funções de GRH tem sido criticada por impor novas e mais pesadas limitações aos gerentes em razão de suas conseqüências não intencionais. No Reino Unido, a eliminação de controles centrais de pessoal e a criação de agências autônomas dentro do serviço público foram acompanhadas por novas formas de regulação, que levaram a um aumento no número de reguladores e à crescente tendência à codificação de normas e convenções antes não escritas (Hood et al., 1999).

Juntos, esses desdobramentos ressaltaram a necessidade de uma abordagem equilibrada à reforma de GRH, como recomendado pelos participantes de uma oficina ONU/DESA (Departamento de Assuntos Econômicos e Sociais), "Construindo o capital humano no serviço público", realizada no $5^{\circ}$ Fórum Global Reinventando o governo (México, novembro 2003). A reunião concluiu que "embora a delegação do recrutamento de servidores por agências centrais... tenha sido efetiva no geral, a existência de mecanismos adequados de supervisão e controle de qualidade nessa área é essencial para evitar abusos e más práticas" (United Nations, 2005). Isso continua sendo um desafio organizacional chave para governos, incluindo os que seguiram o caminho da NGP. 


\section{Quadro 2: O papel das TICs na promoção de uma GRH descentralizada - Camarões}

Antes de 2002, a gestão dos servidores do Estado na República dos Camarões era centralizada em dois ministérios: o Ministério do Serviço Público e da Reforma Administrativa (MINFOPRA) para desenvolvimento de carreira e o Ministério da Fazenda e Orçamento (MINFIB) para salários e aposentadorias. Esse arranjo de gestão, no entanto, havia, gradualmente, resultado em atrasos significativos no processamento de registros de servidores; fraca accountability em relação ao desempenho individual e organizacional; e aumento dos gastos com salários em razão da deficiência dos mecanismos de verificação do número real de servidores.

A natureza centralizada do sistema de gestão de pessoal também significava que outros ministérios, embora responsáveis pelo trabalho realizado por sua equipe, tinham pouca ou nenhuma influência nos assuntos relacionados à promoção, ao desenvolvimento ou à aplicação de sanções no caso de baixo desempenho. Também era muito difícil determinar com precisão o número total de empregados do Estado, com números conflitantes do MINFOPRA e do MINFIB, criando incertezas em relação à conta de salários.

Assim, o governo decidiu embarcar em um novo programa para fortalecer a GRH no setor público. Uma parte importante da agenda de reforma era delegar a GRH para o nível ministerial. Para facilitar esse processo, o governo desenvolveu um sistema integrado informatizado de servidores estatais e de gestão da folha de pagamento, conhecido pela sua sigla, em francês, como SIGIPES, que centraliza todas as informações relacionadas a pessoal e folha de pagamento no serviço público. Desde então, o sistema tem sido implementado em caráter experimental em quatro ministérios: MINFIB, MINFOPRA, Ministério da Educação e Ministério da Saúde.

Como conseqüência do SIGIPES, gerentes seniores do governo têm agora acesso a informações atualizadas sobre salários e pessoal. Além disso, o sistema fornece acesso on-line sobre o andamento de processos relacionados à seleção, promoção, treinamento e aposentadoria. Gerentes seniores no MINFOPRA podem também buscar dados no SIGIPES e assegurar que procedimentos apropriados estão sendo seguidos pelos servidores que administram o sistema. Ao tornar procedimentos governamentais mais transparentes e reduzir a necessidade de interação entre servidores e clientes, a eficiência e transparência da GRH aumentaram e as oportunidades de corrupção diminuíram, um dos benefícios-chave do SIGIPES. A efetiva implementação do sistema também deveu-se à segurança dos dados que circulam no sistema, à qualidade das soluções de hardware e software, e à qualidade do treinamento dos funcionários envolvidos em sua operação.

Um fator primordial do sucesso do SIGIPES foi a abordagem passo-a-passo para sua implementação pelo MINFOPRA, somada à precisão das informações e completa transparência. Em 2004, o MINFOPRA recebeu, pelo SIGIPES, o Prêmio para o Serviço Público das Nações Unidas. Como resultado de seu sucesso na fase piloto, o SIGIPES está agora sendo expandido para outros ministérios na República dos Camarões. 


\section{Profissionalizando a gestão de recursos humanos}

\section{Unidades de GRH: em direção à especialização estratégica}

Nossas licões aprendidas mostraram a necessidade de abordagens mais coletivas e horizontais a todos os aspectos da gestão no serviço público. Isso é reforçado pela constatacãa de que as pessoas são o capital crítico de uma organização moderna e baseada no conhecimento. Devemos disputar por profissionais de conbecimento em um ambiente em que se antecipa um numero significativo de aposentadorias em organizações do setor público e privado e, nesse sentido, um plano estratégico torna-se necessário para o sucesso futuro.

Government of Canada (2001)

Todo governo precisa desenvolver um enunciado de política pública, que defina como a gestão de pessoas contribuirá para a consecução de seus objetivos estratégicos. Esse enunciado não muda da noite para o dia - uma característica intrínseca dos objetivos estratégicos é que eles não são facilmente reversíveis - mas é provável que mude quando um novo partido, com seus próprios objetivos ou "manifestos" (para usar a linguagem da política) assuma o poder. Na verdade, pode mudar até se o partido, atualmente no governo, retornar ao poder após uma eleição, na medida em que o partido tenha apresentado um novo "manifesto" ao eleitorado para ganhar novo mandato. Para ter alguma validade, uma estratégia deve ser considerada importante, não deve ser facilmente reversível e deve envolver comprometimento de recursos governamentais durante um período significativo (GERRY; Scholes, 2002). O tempo e o esforço dedicados serão justificados somente se a estratégia não for automaticamente descartada a cada troca de governo.

Ela deve, ainda, ser abrangente e consistente. A partir da metade da década de 1990, o Departamento do Serviço Público e Administração da África do Sul elaborou planos bastante detalhados para dar forma a sua ambição de "transformar" o serviço público de uma burocracia de comando e controle em instrumento de prestação de serviços aos cidadãos. Muitas vezes, no entanto, a estratégia de GRH pública, assim como no setor privado, pode ser fragmentada e emergente. Um exemplo disso ocorreu ao final dos anos 90, com a decisão estratégica do governo de Botsuana de se tornar um "seguidor" de salários em vez de um "líder", ou seja, seguir as diretrizes salariais em curso no setor privado ao invés de estabelecer suas próprias diretrizes de maneira racional, mas isolada. Os governos precisam reconhecer os grandes benefícios de gerir o seu pessoal estrategicamente, de tal forma que eles contribuam para a consecução dos objetivos políticos e de desenvolvimento do governo.

Qual seja a estratégia de GRH adotada pelo governo, será necessário fornecer apoio profissional nessa área aos gerentes responsáveis pelas decisões a respeito dos servidores. Esse apoio é necessário porque tais decisões são complexas e existe um conjunto de boas práticas profissionais que ajudarão os gerentes a decidir da melhor maneira. Contudo, à exceção de muitos governos que contam com quadros ou corpos profissionais e não raras vezes prestigiados em algumas áreas, com membros que incluem graduados em academias consagradas como a École Nationale d'Administration (Escola Nacional de Administração Pública) da França, a 
função de GRH é comumente descartada por administradores generalistas, aparecendo abaixo de um quadro ou corpo administrativo ou estrutura similar.

No início dos anos 1990, um estudo sobre como os governos gerenciam seu pessoal em três países africanos - Quênia, República da Tanzânia e Zimbábue demonstrou que os servidores responsáveis pelos recursos humanos desempenhavam papel restrito, burocrático e reativo, limitado a decisões rotineiras sobre o direito a aumentos salariais e tópicos semelhantes, algumas das quais poderiam simplesmente ser extraídas pela leitura das normas administrativas que regem o comportamento dos servidores. Eles contribuíam pouco ou quase nada para as decisões estratégicas sobre a gestão de servidores e sobre como atingir os objetivos principais do governo. O estudo observou que esse estilo de GRH deriva de três fatores:

- o "culto ao generalista", que os governos independentes herdaram das antigas potências coloniais, em que a GRH era vista como aspecto singelo e não profissional da administração geral;

- a abordagem inflexível e centralizada à gestão de pessoas, planejada para conter a incidência sempre presente de favoritismo e corrupção limitando o poder discricionário dos órgãos da linha de frente e gerentes; e

- a ausência de modelos alternativos de GRH e de especialistas em GRH (TAYLOR, 1992).

Estudos mais recentes demonstraram que esse papel limitado permanece especialmente difundido em países em desenvolvimento e não apenas nos países africanos citados.

Qual o melhor modelo de funcionamento da GRH que possibilitaria que os governos administrem seus servidores de forma a alcançar seus objetivos-chave? Um modelo amplamente aceito, desenhado para organizações em que os gerentes de linha tomam decisões de rotina sobre os servidores - aqui chamado "especialização estratégica” - esboça os seguintes papéis:

- Especialista em estratégia: o papel estratégico da GRH;

- Especialista em organização do trabalho: o papel profissional em que os servidores da GRH são especialistas em atividades

"Na era do ajuste, quando muitos governos tentavam reduzir o número de servidores, os ministérios do serviço público eram vistos pelos ministérios econômicos como um cavalo de Tróia dentro do governo, atuando como um sindicato informal para frustrar os objetivos da reforma."

como seleção e treinamento e podem assessorar os gerentes de linha sobre como elaborar um processo seletivo, um curso de treinamento, etc.;

- Defensor do empregado: o papel de "porta-voz", transmitindo as preocupações dos empregados a respeito das condições de trabalho aos gerentes seniores (por exemplo, a preocupação de que um programa de downsizning irá aumentar, 
desproporcionalmente, a carga de trabalho dos servidores remanescentes); e

- Agente de contínua transformação: o papel de desenvolvimento da organização, atuando como conselheiro em processos de gestão de mudanças, tais como as etapas pelas quais os órgãos devem passar ao implementar um programa de desenvolvimento de competências (Ulrich, 1998).

Servidores que desempenham esses papéis devem ser especialistas, assessores, consultores ou parceiros nas mesas de negociação. Precisam ter sólido conhecimento acerca do ambiente no qual a organização opera e habilidade de prestar serviços de forma eficiente. A trajetória de carreira típica de um servidor público generalista, que pode, anteriormente, ter sido servidor local e esperar tornar-se presidente do conselho estatutário posteriormente, é inadequada. Os governos precisarão investir no treinamento de seus próprios gestores ou indicar especialistas em GRH de fora da administração para tornar a gestão de pessoas mais eficiente. Especialistas em GRH também precisam ser levados a sério por servidores mais antigos e políticos, se pretendem influenciar a gestão estratégica de recursos humanos no serviço público.

\section{Quadros de competência: estabe- lecendo o padrão de desempenho}

\begin{abstract}
É minha esperança que as competências nos fornecerão uma linguagem compartilhadapara o diálogo, em termos concretos, sobre alto desempenho e excelência gerencial. Acredito que uma visão compartilhada sobre os padrões que nos esforçamos para atingir nos auxiliará em nossos continuos esforços de preparar a Organização para vencer os desafios do século XXI.
\end{abstract}

Kofi Annan

(Secretário-geral da ONU) ${ }^{1}$
A aplicação de um modelo baseado em competências integrado é importante para as boas práticas de GRH no serviço público. Ao promover uma abordagem consistente a todas as atividades da GRH, o quadro ajuda a assegurar que a gestão de recursos humanos contribua, de forma efetiva, para a consecução dos objetivos do governo (integração vertical) e para garantir que a GRH como um todo é melhor do que a soma de suas atividades individuais (integração horizontal). Uma finalidade importante para o desenvolvimento desses quadros no serviço público é promover uma linguagem que pode ser compartilhada, uma vez que ela se relaciona com padrões e expectativas de desempenho.

Um quadro de competências desenvolvido pelo Serviço Público Irlandês ilustra essa idéia. Seus autores destacam que "Quando falamos sobre desenvolvimento de competências, estamos falando do desenvolvimento de comportamentos, atributos, conhecimentos e habilidades necessários para o bom desempenho do nosso trabalho, de forma a concretizar o nosso potencial e fornecer serviços de alta qualidade para nosso público" (CENTRE For Management And Organization Development, 2003). O modelo irlandês coloca o quadro de competências no centro da administração do serviço público. Ele descreve 17 competências comportamentais identificadas como relevantes no atual ambiente do serviço público. Uma vez definido, esse quadro pode ser usado em diversas atividades da GRH (Tabela 3).

O desenvolvimento de recursos humanos fornece um exemplo desse uso. Um quadro de competências similar ao usado pelo Serviço Público Irlandês foi empregado na INTAN, a escola de treinamento de servidores públicos na 


\section{Tabela 3: Um quadro de competências para GRH}

\begin{tabular}{l|l}
\hline Atividade da GRH & Uso do modelo de competência \\
\hline Nomeação baseada em mérito & $\begin{array}{l}\text { Atua como um quadro de "especificação } \\
\text { da pessoa", estabelecendo critérios de } \\
\text { seleção }\end{array}$ \\
\hline Salários e gratificações & $\begin{array}{l}\text { Usado na "avaliação do trabalho" para } \\
\text { fornecer base para salários e categorias }\end{array}$ \\
\hline Gestão por desempenho & $\begin{array}{l}\text { Fornece um quadro para gerir o } \\
\text { desempenho dos servidores }\end{array}$ \\
\hline Corte de cargos & $\begin{array}{l}\text { Ajuda a identificar funções prioritárias e } \\
\text { funções que não são mais necessárias }\end{array}$ \\
\hline Desenvolvimento de recursos humanos & $\begin{array}{l}\text { Permite que gerentes e servidores } \\
\text { identifiquem a "lacuna de desempenho" } \\
\text { entre as competências existentes e as } \\
\text { exigências dos cargos }\end{array}$ \\
\hline
\end{tabular}

Malásia, como base para desenvolver competências de gestão em servidores seniores. Nesse programa de treinamento, pediu-se aos servidores que dissessem se as competências específicas constituíam, para eles, pontos fortes ou fracos. Se eles achassem que uma competência em particular precisava ser desenvolvida, eles deveriam listar os passos a serem tomados para desenvolvê-la.

Deve-se notar que um quadro de competências pode ser usado tanto em órgãos públicos que nomeiam profissionais externos para cargos bastante superiores ("ingresso lateral"), como naqueles que fazem promoções internas. No primeiro sistema, as competências podem servir de base para essas nomeações de profissionais de fora; da mesma forma, no segundo, as competências oferecem critério para o desenvolvimento do indivíduo nomeado internamente, que precisa desenvolver competências, que não foram adquiridas na parte inicial da carreira, para exercer o novo cargo.
Nomeação baseada em mérito: selecionando a melhor pessoa para o cargo

Eu considero a aristocracia natural (cuja base é a virtude e o talento) como o mais precioso presente da natureza para a educação, para os fundamentos e para o governo da sociedade.

Thomas Jefferson $(1813)^{2}$

Um serviço baseado em carreiras e orientado pelo mérito é um fator-chave para explicar o desempenho do serviço público. Diversos estudos corroboraram isso e atribuíram o crescimento econômico e a redução da pobreza às características institucionais da nomeação baseada no mérito e da estabilidade da carreira (JAMES; Evans, 2000). A construção de um serviço público meritocrático é de importância universal para o desempenho (ANDERSON; REID; Ryterman, 2003) e significa lançar mão de talentos em grupos sub-representados, de forma a assegurar que os serviços 
públicos representem adequadamente todos os segmentos da sociedade.

Mérito pode ser definido como "a indicação da melhor pessoa para determinado cargo"; é o impulso do ideal napoleônico francês de "une carrière ouverte aux talents". Assim, em um sistema meritocrático puro, todas as nomeações públicas, de alto para baixo, são precedidas de uma competição baseada em regras de mérito publicizadas e passíveis de questionamento se houver suspeita de violação. Embora a definição em si seja trivial e não controversa, há quatro situações em que a aplicação do princípio do mérito choca-se com a prática da administração.

\section{Exceções ao mérito e à seleção competitiva}

Provavelmente nenhuma administração opera um sistema puramente de mérito ou de seleção competitiva. Por definição, porém, é a "melhor pessoa" que irá prestar o serviço de melhor qualidade ao público. Portanto, é de extrema importância que o serviço público consiga atrair uma boa parcela dos melhores talentos do mercado de trabalho. As exceções demonstram que nem sempre é "prioridade zero" do governo selecionar o "melhor". Essa afirmação requer uma justificativa para cada caso:

- agentes públicos eleitos: alguns agentes são eleitos e não nomeados;

- nomeações políticas: os agentes públicos eleitos podem escolher alguns assessores políticos. Pode haver relativamente muitos deles, como nos Estados Unidos, ou poucos, como no Reino Unido, mas, na maioria dos casos, eles deveriam ser restritos à equipe senior que trabalha diretamente para os políticos, o que impõe um desafio para administrações em que há muitos cargos políticos. É necessário ter em mente que alguns sistemas do serviço público com grande número de nomeações políticas, como na França e nos Estados Unidos, são, às vezes, orientados por mérito, por causa da natureza seletiva e competitiva do processo de seleção;

- ação afirmativa: muitas administrações, entre elas as da Malásia, Irlanda do Norte e Estados Unidos, vem utilizando "cotas" e similares em nomeações públicas para agilizar a ascensão de membros de grupos em desvantagem, tais como mulheres e determinados grupos étnicos como a maioria indígena na Malásia ou a minoria católica da Irlanda do Norte. Um sistema de cotas minuciosamente especificado pode ter legitimidade democrática, mas também é possível haver alternativas que preservem o mérito;

- nomeações e transferências internas; discricionariedade do gerente local: a maior parte das administrações restringiram determinados tipos de promoções a servidores já pertencentes ao quadro como forma de minimizar custos de transação e oferecer oportunidades de desenvolvimento na carreira. Do mesmo modo, gerentes locais têm liberdade para fazer algumas nomeações;

- outras nomeações: planos de transição, cessões de servidores, realocação de tarefas, terceirizações, etc. constituem outras maneiras de a administração preencher cargos específicos.

É razoável que o mérito seja repelido em alguns casos: seria perverso, por exemplo, em nome da "justiça”, abolir um sistema de transferência que tenha sido introduzido para minimizar a corrupção. Contudo, com a óbvia exceção de agentes públicos eleitos, ainda deve haver um procedimento adequado que preserve o 
mérito tanto quanto possível. Preferencialmente, ele deve constituir uma versão minimamente adaptada ao procedimento normal, de forma que a transparência seja preservada tanto quanto possível. No entanto, os fatores acima mencionados encontram-se freqüentemente em tensão com o princípio do mérito, demandando difíceis julgamentos em casos particulares.

Há também circunstâncias nas quais o mérito é desprezado em vez de afastado e outras em que há necessidade de promovê-lo. É o caso da corrupção financeira, mas há também outros obstáculos como o apadrinhamento político (clientelismo) e o nepotismo; as várias formas de discriminação; a má definição do "princípio do mérito"; e a politização do serviço público.

\section{Internalizando o princípio do mérito}

O papel do arranjo institucional pode ser minimizado onde o princípio do mérito está internalizado e é policiado por pressão dos colegas (no jargão da gestão moderna, pode-se dizer que a cultura está desempenhando algumas das funções da estrutura). Assim, no Reino Unido, a função central de seleção foi, na verdade, privatizada e todas as funções operacionais foram delegadas a departamentos de linha de frente. $\mathrm{O}$ argumento de que outros países devem, em certa medida, fazer algo parecido foi vigorosamente defendido (Anderson; Reid; Ryterman, 2003), embora a estrutura descentralizada nem sempre seja apropriada, conforme discutido anteriormente neste capítulo. Contudo, outros arranjos institucionais devem ser considerados, como:

- estabelecimento de uma agência central de recrutamento e seleção (discutido acima no contexto do marco legal);
- disposições legais (como, por exemplo, a perseverança da Polônia no sentido de desenhar uma lei do serviço público ao longo de várias mudanças de governo);

- separação da esfera política da administrativa;

- estabelecimento de um serviço sênior de "elite" (como na Argentina); e

- Elaboração de um código de conduta interno.

Os arranjos acima sugeridos não irão abolir o apadrinhamento da noite para o dia; na verdade, eles são constantemente ameaçados pelas próprias pressões que visam conter. No entanto, a evidência de países como Singapura é que a persistência cria, pelo menos, uma zona que pode ser usada como base para expandir a influência do mérito.

\section{Como identificar o mérito}

Tanto as questões macro quanto as micro são importantes para a seleção: de nada adiantam os arranjos institucionais elaborados se o conteúdo do processo de seleção não for aprimorado. $\mathrm{O}$ mérito não é auto-evidente e a justiça deve ser vista para ser feita. As administrações muitas vezes aplicam esses "truísmos" adotando um sistema de concursos competitivos em estilo universitário, como no Paquistão e na República da Coréia, ou pelo exame das qualificações educacionais, como em Singapura. Tais métodos são justos e detêm confiança pública. Contudo, não reconhecem o mérito, uma vez que há pouco vínculo entre o que é testado e as exigências do trabalho (uma meta-análise encontrou uma relação estatística muito baixa entre as qualificações e o desempenho no trabalho).

Por outro lado, testes de seleção comerciais sofisticados, amplamente usados em países ocidentais, não estão 
disponíveis para venda na maior parte dos países em desenvolvimento e economias de transição e recriá-los exigiria uma massa crítica de psicólogos organizacionais que poucos países em desenvolvimento possuem. Além disso, tais métodos não se justificariam para a maior parte das nomeações públicas, inclusive nomeações para trabalhos manuais (neste contexto, os trabalhos manuais são tão importantes quanto os de profissionais seniores). Felizmente, outros métodos válidos e praticáveis estão disponíveis: boa prática não é uma prerrogativa apenas dos ricos.

À luz da pesquisa e da prática organizacional, um bom procedimento de nomeação terá oito elementos (deve-se observar que a lista inclui o desenvolvimento de competências, um segundo exemplo de como essa atividade é crucial na GRH):

- uma análise das atribuições do cargo, que resulte na descrição, por escrito, das atribuições (descrição das funções) e das competências necessárias para seu exercício (o quadro de competência ou especificação da pessoa);

- um anúncio disseminado para os gruposalvo interessados, incluindo um resumo da descrição das funções;

- um formulário de inscrição padrão;

- um esquema de pontuação baseado na especificação da pessoa;

- um procedimento de eliminação (shortlisting) para reduzir o número de formulários enviados, se necessário, a um número mais plausível;

- um procedimento de seleção final baseado na especificação da pessoa e incluindo uma entrevista com uma banca;

- um procedimento de nomeação baseado no esquema de pontuação; e

- informação dos resultados a candidatos selecionados e não selecionados.
O formato de "centro de avaliação", contendo vários métodos de seleção que incluem entrevista e atividades orais e escritas conforme o caso, continua sendo o padrão de ouro da seleção pública. É utilizado em vários países que tomaram emprestado o modelo do Reino Unido. Pesquisa recente demonstra, no entanto, que a validade da impopular entrevista realizada por banca pode equiparar-se à de um centro de avaliação, caso seja bem estruturada, baseada na análise das atribuições do cargo, conduzida por entrevistadores treinados e culmine com uma nomeação que reflita a pontuação independente dos membros da banca. Entretanto, a utilização de um segundo método na etapa final da seleção pode oferecer uma visão diferente, às vezes corretiva, do candidato.

As práticas de mérito não são universais mesmo em governos de países industrializados. Além disso, as nomeações não são feitas em um vácuo organizacional e são afetadas pelo clima geral, bem como pelas práticas que as rodeiam. Dito isto, ressalte-se que fortalecer a nomeação baseada no mérito é uma das maneiras mais simples e poderosas de os governos melhorarem sua eficiência.

\section{Desenvolvendo uma política} salarial: atrair e reter talentos

\footnotetext{
Quando os salários no governo caem, tanto em termos absolutos quanto em relação a atividades remuneradas alternativas, ofuncionalismo público se adapta à nova situação ${ }^{3}$.
}

Mudanças demográficas e de outros fatores do mercado de trabalho, tais como a crescente competição por talentos no setor privado e não-governamental, estão tornando o recrutamento e a retenção de 
pessoal de qualidade uma questão cada vez mais crítica para o setor público. Salários adequados são amplamente considerados um componente-chave para melhorar e manter a motivação, o desempenho e a integridade dos servidores públicos (Kiragu; Mukandala, 2003). Por outro lado, baixos salários levam a absenteísmo, empregos alternativos e adicionais, corrupção e baixa produtividade. Portanto, o desenvolvimento de uma política salarial faz parte de uma GRH estratégica no serviço público.

Contudo, assolados por limites orçamentários e envolvidos, de um lado, em negociações com sindicatos, e, de outro, com doadores, os governos facilmente esquecem a que o salário se presta. $\mathrm{O}$ objetivo de uma política salarial deveria ser pagar aos servidores públicos o suficiente para atrair e reter pessoas competentes. Manter o desempenho e a motivação dos servidores públicos também deveria ser uma consideração importante no desenvolvimento de uma política salarial. Por exemplo, com salários acima do ponto de equilíbrio - e havendo flexibilidade suficiente no mercado de trabalho para tal - tende-se a aumentar o custo de oportunidade para pessoal com produtividade decrescente. Salários mais altos podem, portanto, promover a orientação para o desempenho no serviço civil.

Botsuana é um exemplo de país que utilizou o salário como elemento-chave para atrair e reter servidores de qualidade no setor público. A Comissão Presidencial de Revisão da Política de Receitas de 1990 desempenhou papel crucial nesse sentido. O governo permitiu que forças de mercado determinassem as faixas salariais e também atuou no sentido de "descomprimir" os salários, de modo que a relação entre os servidores públicos mais bem pagos e os menos bem pagos se ampliasse significativamente entre os anos 1980 e 2002. Seus salários hoje se encontram entre os mais altos dos países da África Subsaariana (Kiragu; MuKandala, 2004).

O fato de Botsuana ter conseguido realizar uma reforma salarial significativa no serviço público sem dúvida deve-se, em parte, às riquezas naturais do país - no caso, diamantes. Contudo, Botsuana não é

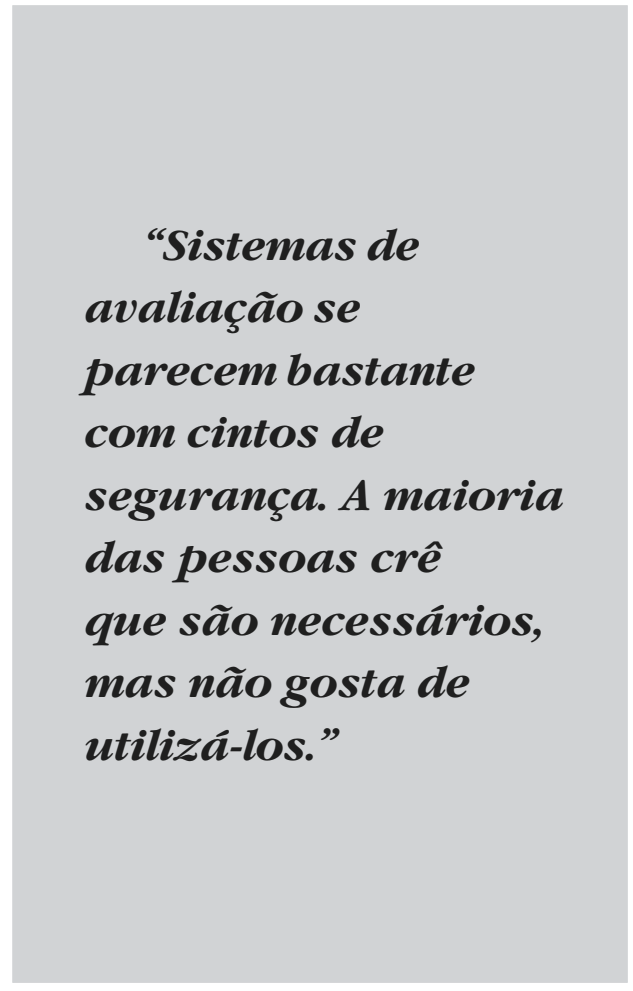

o único país em desenvolvimento abençoado com dotações consideráveis de recursos naturais de valor. Diversos outros países em desenvolvimento contam com um patrimônio natural semelhante, mas não conseguiram melhorar as condições de trabalho para o funcionalismo público. O que parece ter feito a diferença é a gestão estratégica e efetiva da receita gerada por parte das instituições públicas, bem como 
um compromisso genuíno da liderança com a reforma.

Apesar de o desenvolvimento de uma política salarial ser uma questão inevitavelmente política e delicada, governos e doadores internacionais muitas vezes sucumbem a uma ingenuidade específica: supor que os governos podem realizar qualquer coisa que desejarem, se simplesmente tiverem a determinação de fazê-lo. No entanto, restrições políticas e fiscais determinam que a maioria dos governos de países em desenvolvimento não pode simplesmente realizar uma reforma salarial racional e ideal. O presidente Soglo, do Benin, havia anteriormente atuado como diretor regional do Banco Mundial, mas foi incapaz de levar a cabo sua tão desejada reforma salarial em função da oposição dos sindicatos de servidores públicos e de membros do Parlamento, levando por fim à sua derrota na eleição presidencial de 1996.

Isto não significa que os governos são obrigados a ceder, entregando-se ao lobby político, como o dos sindicatos de servidores públicos. Ao invés disso, um governo precisa chegar a um equilíbrio delicado entre o que é ideal e o que os stakeholders mais importantes irão aprovar, mantendo um programa de reforma gradual ao longo de vários anos. Todo governo precisa levar em consideração restrições políticas, bem como fiscais, quando se trata de decisões salariais no serviço público. Como o processo é sempre intensamente afetado pelas políticas e pela escassez de recursos, nem sempre é possível dar-se ao luxo de uma política ideal.

Uma política salarial não determina a viabilidade financeira; ela é, isto sim, uma restrição imposta pelo orçamento. Gastos com salários não deveriam ser orçados sem levar em consideração outros gastos governamentais. Por exemplo, exaurir o orçamento com salários dos professores e médicos pode restringir a aquisição de livros e medicamentos. O importante é alcançar um mix ideal de gastos em termos de objetivos estratégicos, ao invés de simplesmente estabelecer uma meta exclusivamente para despesas com salários.

\section{Elementos-chave de uma abordagem estratégica}

Uma política salarial deveria ser estratégica no sentido de satisfazer minimamente os stakeholders, ao mesmo tempo em que se pensa mais à frente. A alternativa seria ser "reativo", com um governo à mercê de grupos de interesses cuja força muitas vezes tem pouco a ver com a sua contribuição para a consecução dos objetivos do governo. Portanto, um governo precisa começar com uma estratégia adequada para as circunstâncias. No ambiente político, é necessário realizar um delicado número de malabarismo, equilibrando prioridades e interesses-chave dos stakeholders, assim como a eqüidade e a motivação, ao desenvolver políticas salariais. Uma estratégia salarial normalmente envolverá as seguintes questões:

- alinhar os salários com os objetivos políticos gerais do governo, o que inclui identificação de todos os grupos de servidores (por exemplo, professores de ensino fundamental) que atualmente estejam recebendo salários demasiadamente altos ou baixos nas áreas às quais o governo deseja dar prioridade. É desta forma que os salários contribuem para alcançar dos objetivos estratégicos do governo;

- determinar a base salarial e, em especial, a mistura adequada entre os seguintes fatores primários e secundários: 
- Fatores primários:

* Disponibilidade orçamentária (por ex., restrições orçamentárias)

* Conteúdo da função exercida, possivelmente baseada na "avaliação do trabalho"

- Fatores secundários

* Custo de vida

* Salários baseados no mercado

* Desempenho individual

* Qualificações

- estabelecer uma "relação de compressão" adequada entre os servidores mais e menos bem pagos, e

- alcançar equilíbrio entre salários, outros benefícios (inclusive aposentadoria) e outros subsídios. É importante reconhecer que a remuneração não-monetária (tais como moradia) e promessas de benefícios a serem pagos no futuro (tais como pensões) são uma despesa corrente; caso contrário, os salários do serviço público estarão sendo significativamente sub-avaliados.

\section{Equilíbrio entre eqüidade e motivação}

Governos são geralmente obrigados a se comprometer politicamente com salários eqüitativos até mesmo quando fatores de mercado ou desempenho não o justificam. Sob algumas circunstâncias, contudo, manter salários eqüitativos simplesmente não é viável. Em primeiro lugar, vincular salários eqüitativos a um "salário mínimo" pode parecer a decisão "certa"; todavia, em países de renda per capita extremamente baixa, isso equivale a premiar servidores de nível mais baixo, o que aumenta o risco de inchamento do serviço público. Em segundo lugar, com níveis salariais equiparáveis ou até mesmo inferiores a salários de mercado, um serviço público inchado na base da pirâmide e remunerado de forma eqüitativa pode acabar minando outros projetos vitais de gastos governamentais. Portanto, o pagamento eqüitativo não é viável sem um serviço público rightsiz̨ed, ou seja, redimensionado para um tamanho correto.

A motivação, por outro lado, inclui o uso de diferenciais salariais para dar ao funcionalismo público incentivos para buscar responsabilidades de nível mais alto. Os sistemas de serviço público civil tradicionalmente basearam suas escalas salariais em qualificações formais e no conteúdo da função e não em fatores de mercado. Em anos recentes, entretanto, em especial com referência ao modelo NPM, os governos tornaram-se cientes de que precisam vincular seus salários aos praticados no mercado a fim de atrair e reter os talentos necessários para melhorar e dar sustentação ao desempenho do setor público. Quando a desigualdade de renda entre servidores é deliberadamente aumentada, as posições no alto escalão tornam-se mais atraentes. Isto é realizado por meio da "descompressão salarial", o que significa aumentar a relação entre os salários do topo e os da base. Quanto maior a relação, maior a descompressão de salários, e vice-versa. O pressuposto de uma descompressão simultânea à manutenção dos gastos em níveis constantes é que os escalões mais baixos de servidores são pagos acima do valor de mercado, enquanto os os mais altos são sub-remunerados.

Conforme mostra a Tabela 4, alguns países optam por uma estrutural salarial mais igualitária, enquanto outros operam com um diferencial salarial maior entre os níveis mais altos e os mais baixos do serviço público civil. $\mathrm{Na}$ teoria, uma estrutura salarial igualitária é mais atraente para os escalões inferiores do serviço 
Tabela 4: Relação de compressão de escala salarial, 1991-2003

\begin{tabular}{l|c|c|c}
\hline País & Anterior & Final & Período de referência \\
\hline Camboja & -- & 2 & 2002 \\
\hline Cabo Verde & 5 & 7 & $1991-2001$ \\
\hline Gâmbia & 8 & 7 & $1992-2003$ \\
\hline Guiné & -- & 2 & 2002 \\
\hline Madagascar & 3 & 5 & $1997-2002$ \\
\hline Mali & 7 & 6 & $1994-2003$ \\
\hline Mauritânia & 2 & 2 & $1993-2002$ \\
\hline Paquistão & 9 & 10 & $1994-2002$ \\
\hline Peru & -- & 3 & 2002 \\
\hline Senegal & 5 & 4 & $1994-2001$ \\
\hline Suriname & 6 & 3 & $1997-2002$ \\
\hline Timor-Leste & 4 & 4 & $19902-2004$ \\
\hline Togo & 4 & 4 & 1999 \\
\hline Tonga & -- & 7 & $1995-1997$ \\
\hline Uganda & 4 & 5 & $1994-2004$ \\
\hline Estados Unidos & 6 & 6 & 1998 \\
\hline Iêmen & -- & 3 & \\
\hline
\end{tabular}

Fontes: UN/DESA, com base nos relatórios nacionais do FMI, relatórios do Banco Mundial e estatísticas nacionais.

Nota: A relação de compressão é calculada como sendo a relação entre a média do nível salarial mais alto e a média do nível salarial mais baixo, sempre que possível.

público civil, enquanto estruturas salariais com maior descompressão provavelmente levarão ao recrutamento e à retenção de talentos que, caso contrário, possivelmente passariam para a iniciativa privada.

\section{Escopo das gratificações}

A maioria das pessoas concordaria que Camboja, Guiné e Mauritânia, onde a relação salarial média entre o nível mais alto e o mais baixo era de apenas 2, necessitavam de "descompressão". Os governos, no entanto, também precisam levar em consideração subsídios e benefícios em espécie. Por exemplo, a relação de compressão moderada de Uganda em meados dos anos 1990 mudou para 1:100 após a inclusão de benefícios nãomonetários (GOVERNMENT OF UGANDA, 1994). Isto é freqüente em diversos níveis, especialmente em países em desenvolvimento. Na Zâmbia, por exemplo, os secretários permanentes recebem 50 vezes mais do que os servidores do nível mais baixo do serviço público quando subsídios e benefícios em espécie (moradia, carros, telefones, etc.) são levados em conta. Contudo, ao se excluirem tais benefícios, a diferença é de somente cinco vezes (KeuleERs, 2004). 
Em muitos países em desenvolvimento, subsídios e benefícios em espécie desempenham papel substancial na remuneração de servidores do setor público, motivo pelo qual chegar a um equilíbrio entre salários e benefícios e subsídios é tão importante. Um passo inicial em direção a uma reforma salarial é considerar a monetarização de tais benefícios a fim de evitar o abuso de privilégios indefinidos e direitos adquiridos para servidores públicos. Em 2002, a Nigéria adotou uma política de monetarização para verificar os custos crescentes de se oferecer benefícios em áreas tais como hospedagem, transporte, alimentação, despesas com serviços públicos (energia elétrica, água, etc.), empregados domésticos, férias, medicamentos, móveis, veículos e motoristas. Os custos de tais amenidades tornaram-se tão substanciais que deixavam pouco espaço para o financiamento de outras prioridades governamentais, por exemplo, projetos importantes. Contudo, a evolução recente da Nigéria mostra que a monetarização de benefícios tem seu preço, pelo menos em termos políticos. Apesar de a remuneração não-transparente ser ineficiente e não-eqüitativa, "aumentar a transparência de forma prematura provavelmente irá gerar pressão descontrolada e impossível de ser sustentada em prol da equalização de benefícios e de aumentos salariais generalizados" (GARNETT; STEVENS, 2000).

Além disso, onde a corrupção e empregos secundários prevalecerem, provavelmente os servidores públicos mais antigos irão obter mais destas fontes do que seus colegas mais jovens, mais uma vez atenuando os efeitos da compressão salarial. Deve-se observar que a descompressão salarial provavelmente será negativa em termos de gênero, na medida que os servidores públicos mais antigos são predominantemente masculinos. Uma reforma salarial ampla precisar levar em consideração todos esses fatores e não simplesmente os níveis salariais "mais gritantes", as quais, apesar de serem um ponto de partida, normalmente fornecem uma imagem incompleta dos rendimentos efetivos dos servidores públicos mais antigos. Também é preciso manter em mente que a multiplicidade de fontes de renda dos servidores mais antigos aumenta os custos administrativos do sistema de folha de pagamento do governo.

Na maioria dos países desenvolvidos, os subsídios e benefícios em espécie desempenham um papel bastante pequeno na remuneração total do funcionalismo público. Em meados da década de 1990, por exemplo, o salário-base dos servidores públicos da França e da Alemanha respondia por $70 \%-90 \%$ e $75 \%-95 \%$ da remuneração total, respectivamente, e, nos países nórdicos e anglo-saxões, ela respondia por praticamente $100 \%$ do total (OECD, 1995).

Embora oferecer incentivos para aspectos tais como antigüidade ou nomeação para cargos não-atraentes tenha seu mérito, o desenvolvimento de tabelas de salários e complementos adicionais abrangentes e customizados tem seu preço. No Peru, por exemplo, somente $41 \%$ de todos os pagamentos de salário foram computados na folha de pagamento formal nos últimos anos. O restante da conta salarial cobria 40 diferentes complementos salariais, seja em dinheiro ou em espécie. Conseqüentemente, servidores com o mesmo nível salarial e desempenhando mais ou menos as mesmas funções corriam o risco de receber salários muito diferentes. O resultado líquido era que a coesão interna dos níveis salariais no serviço público do Peru tornou-se 
excessivamente distorcida, podendo, em casos excepcionais, até mesmo a remuneração máxima do nível mais baixo ser maior do que o salário máximo registrado para vice-ministros (WORD BANK, 2002). Como resposta a esses efeitos adversos dos complementos customizados, a Lei do Sistema de Remuneração do Serviço Público foi adotada em 2005.

\section{Competitividade salarial do setor público}

Igualmente - ou até mesmo mais importante é a competitividade salarial do setor público vis-à-vis à da iniciativa privada. Normalmente acredita-se que os salários no setor público sejam muito mais baixos do que na iniciativa privada. Contudo, essa conclusão pode não se aplicar a todos os níveis salariais do serviço público. Por exemplo, os salários do setor público na América Latina e no Caribe tendem normalmente a ser menores do que aqueles oferecidos pelo setor privado, o que pode não se aplicar aos cargos que demandam grau menor de competências. Enquanto os altos escalões do setor público muitas vezes recebem salários significativamente inferiores àqueles percebidos por seus pares no setor privado (cerca de $25 \%$ a $35 \%$, de acordo com um estudo), não é raro ocorrer paridade nas funções não-qualificadas (REID; SCOTT, 1994). A experiência de países da América Latina e Caribe também indica que quanto maior qualificação uma função no setor público exigir, tanto maior o diferencial salarial em relação ao setor privado.

Tais constatações não estão limitadas à América Latina e ao Caribe. Exemplos de países tão diferentes quanto Guiné, Paquistão e a antiga República Iugoslava da Macedônia ilustram a necessidade de se olhar tanto para a taxa de compressão quanto para os diferenciais salariais entre os setores público e privado a fim de realizar uma comparação equilibrada de salários em todos os níveis. No Iêmen, por exemplo, a taxa de compressão no governo era de somente 1:3 no final dos anos 1990 . Da mesma forma, executivos seniores no setor privado recebiam salários nove vezes maiores do que aqueles recebidos por seus pares do setor público, enquanto a remuneração no nível de serviços de apoio era três vezes superior à do setor público, apesar de esta comparação não incluir os baixos salários pagos pela economia informal (World BANK, 2000). Sob tais circunstâncias, atrair e reter os mais talentosos torna-se bastante improvável.

Às vezes, as diferenças salariais entre os setores público e privado podem até mesmo parecer absurdas, conforme ilustrado por alguns exemplos. Em Moçambique, no início dos anos 1990, por exemplo, as diferenças salariais eram tão distorcidas que um faxineiro empregado por uma organização internacional recebia um salário equivalente ao de um diretor no setor público. No final dos anos 1990, contudo, esta relação havia melhorado, de modo que um motorista empregado no setor privado recebia o equivalente ao salário de um professor de uma universidade pública. Entretanto, consideradas as visíveis diferenças de padrão de vida, os pagamentos associados a um segundo emprego (nãooficial) e à corrupção - ou o que muitas vezes era denominado "remuneração secundária" - desempenhavam um importante papel no aumento da renda total (Sulemane; KayizZi-mugeriwa, 2001).

A presença de doadores e organizações internacionais que oferecem altos salários em países em desenvolvimento e economias em transição tem levado, muitas vezes, ao "desvio" de servidores 
altamente qualificados, cuja disponibilidade no mercado de trabalho é relativamente escassa - servidores que, caso contrário, ocupariam altas posições no setor público, conforme demonstrado pelas experiências de Camboja e Moçambique. Ademais, os altos salários de funcionários em Unidades de Implementação de Programas patrocinadas por doadores não raras vezes inibiram a absorção de "fim de carreira" daqueles funcionários pelo setor público. Numa tentativa de atacar tais problemas, na Bolívia alguns doadores multilaterais e bilaterais estão financiando um plano de incremento salarial em ministérios prioritários (Wolrd BANK, 2003).

Desnecessário dizer que há exemplos que desafiam a afirmação geral de que diferenças salariais são a favor do setor privado. No Marrocos, um estudo recente constatou que a compensação monetária no setor público é $8 \%$ mais alta do que no setor privado. No entanto, se todos os subsídios não-monetários forem incluídos nesta comparação, a remuneração total dos servidores públicos no Marrocos seria entre 1,5 e 2 vezes mais alta do que no setor privado. Isto - conclui o estudo pode explicar as filas significativas para emprego no setor público no Marrocos, especialmente por parte de trabalhadores qualificados (Agenor; Aynaoui, 2003).

Em geral, deve-se esperar uma remuneração mais alta no setor privado do que no setor público devido à estabilidade no emprego, benefícios de aposentadoria quase sempre generosos e às taxas mais elevadas de absenteísmo. Nesse sentido, não necessariamente deveria ser objetivo dos governos equiparar compensações com o setor privado de forma geral. Ao invés disso, deveriam visar oferecer remuneração que permita, pelo menos, manter um padrão de vida mínimo para servidores dos níveis mais baixos e, ao mesmo tempo, oferecer incentivos para que dirigentes permaneçam no setor público por meio de uma descompressão salarial adequada.

Caso seja considerado necessário aumentar salários, o governo - em termos ideais - irá torcer para que haja crescimento econômico significativo o suficiente para financiar os aumentos. No entanto, mesmo que o crescimento seja reduzido, pode haver espaço para aumentar as receitas tributárias. O estabelecimento de autoridades fiscais autônomas parece ter melhorado a receita em vários países africanos, incluindo Moçambique e África do Sul. Uganda oferece um exemplo dramático: após o estabelecimento da Autoridade Fiscal da Uganda, a receita aumentou quase cinco vezes entre $1991 \mathrm{e}$ 1996 (Kiragu; Mukandala, 2004).

A prática de delegar a responsabilidade pela arrecadação de (certos) impostos a entidades autônomas - normalmente conhecida como "tax farming" ou terceirização da arrecadação tributária - pode minimizar a atuação governamental e resultar em maior eficácia na arrecadação de impostos (Stella, 1992). Considera-se que a vantagem básica deste sistema é a capacidade de gerar mais receita bruta em comparação à cobrança de impostos diretamente realizada pelo governo. Contudo, o problema é que esta prática tende a tornar-se demasiadamente cautelosa com os recursos empregados em excesso, uma vez que os custos pagos pelos contribuintes, por exemplo, não são levados em consideração, o que, por sua vez, geraria despesas governamentais adicionais no monitoramento, anulando o ganho inicial.

Outra opção é o governo encontrar dinheiro em orçamentos já existentes. Se, por exemplo, Sri Lanka ou Uganda conseguirem um acordo duradouro com os 
rebeldes, os gastos com segurança poderiam diminuir e as economias obtidas poderiam ser redirecionadas para o aumento de salários. Se isto não for possível, todavia, o governo volta para o remédio da era de ajustes estruturais: o corte de alguns empregos a fim de pagar mais às pessoas que realmente importam.

\section{Dados sobre emprego e salários}

Considerando a crescente importância da remuneração para a motivação e retenção de pessoas de talento no setor público, é preocupante que a maioria dos países em desenvolvimento e economias em transição dediquem esforços relativamente pequenos à coleta de dados de qualidade sobre emprego e salários. Por algum motivo, a disponibilidade de bons dados nessa área é muito limitada, dificultando - ou até mesmo impossibilitando medir o custo e a contribuição dos recursos humanos ao desempenho geral do setor público. Este trabalho, portanto, recomenda que os governos dêem maior atenção ao desenvolvimento de melhores sistemas e metodologias para aperfeiçoar a coleta e análise de dados sobre salários e empregos no setor público.

Em primeiro lugar, entretanto, os governos precisam resolver uma série de questões metodológicas essenciais ao processo de coleta e análise de dados sobre empregos e salários no setor público. Isso inclui decidir a respeito do escopo, da oportunidade e da freqüência da coleta de dados, bem como a definição de termoschaves. Dados sobre salários, por exemplo, muitas vezes excluem remunerações não-salariais, conforme discutido anteriormente. Desnecessário afirmar que, ao excluir benefícios tais como pensões, moradia, automóveis, telefones, alimentação e vestuário, cujo valor muitas vezes ultrapassa o salário-base, mina-se a utilidade da coleta de dados nesta área.

Outra questão preocupante é a falta de padrões comuns aos diversos países que permitam a coleta de dados sobre emprego e salários no setor público. Tais dados raramente são comparáveis entre os países, devido a uma série de fatores. Primeiro, os Estados são estruturados de forma diferente, o que inevitavelmente tem implicações para a utilidade comparativa de dados sobre emprego e salários no setor público. Estados centralizados, ceteris paribus, apresentam, em geral, porcentagem maior de gasto com a folha de pessoal, pois um volume menor de transferências financeiras é repassado ao nível subnacional para o subseqüente pagamento de salários de servidores deste nível. Dados sobre salários como porcentagem dos gastos totais do governo central ilustram esse ponto (Tabela 5).

Tabela 5: Salários em Estados federativos x unitários

\begin{tabular}{l|l|c|l}
\hline País & Estado & Percentual & Ano \\
\hline Estados Unidos & Federativo & 8,4 & 1997 \\
\hline França & Unitário & 15,9 & 1997 \\
\hline Índia & Federativo & 9,4 & 2001 \\
\hline Chile & Unitário & 19,4 & 2001 \\
\hline
\end{tabular}

Fonte: UN/DESA, com base nos Indicadores de Desenvolvimento Mundial, do Banco Mundial. Nota: Salários são apresentados como porcentagem do total de gastos do governo central. 
Os governos centrais da Índia e dos EUA, por exemplo, não empregam professores, enquanto os governos centrais do Chile e da França o fazem. Tal fato, obviamente, distorce a comparação entre dados sobre os empregados do governo central e níveis salariais, assim como ocorre com o registro de transferências para os níveis subnacionais, um importante componente dos gastos públicos do governo central em Estados federais. Em segundo lugar, até mesmo quando os Estados estão estruturados de forma semelhante, abordagens divergentes em relação à classificação de emprego no setor público muitas vezes representam um outro grande desafio para comparações entre países. Este problema, às vezes, é agravado pela freqüente reclassificação de setores como resultado das reformas administrativas. Mudanças recentes na prestação de serviços, tais como as terceirizações, distorceram ainda mais o quadro para comparação de dados sobre emprego e salários no setor público em diferentes países.

Concluindo: a disponibilidade de dados precisos, confiáveis, válidos e amplos sobre emprego e salários no setor público está se tornando mais e mais importante para a gestão estratégica de recursos humanos. Portanto, recomendase que os governos considerem o desenvolvimento de metodologias mais apropriadas para a coleta e análise de dados sobre emprego e salários no setor público, tanto em nível nacional como mundial.

Gestão por desempenho e avaliação: apoiar e desenvolver pessoas

Sistemas de avaliação se parecem bastante com cintos de seguranç. A maioria das pessoas crê que são necessários, mas não gosta de utilizá-los'.
Para alguns governos - como é o caso do Marrocos - introduzir a gestão por desempenho e a avaliação é o primeiro passo na reforma da GRH. Isto porque a gestão por desempenho é uma forma de dizer aos gerentes do setor público algo que eles podem não ter ouvido falar antes: eles são responsáveis pelo desempenho do pessoal que trabalha com eles e é função do gerente geri-los, estabelecer objetivos que se relacionem com a estratégia geral, monitorar seu desempenho e dar-lhes apoio, feedback e oportunidades de desenvolvimento.

A experiência em gestão por desempenho de países em desenvolvimento mostra não somente como uma gestão por desempenho eficaz funciona na prática, mas também como ela difere das práticas tradicionais em vigor em muitos órgãos públicos. (Martinez; Martineau, 2000). Em um dos extremos, está a Zambia Electricity Supply Corporation (Zesco) Ltd., que, com a chegada de um novo gerente comprometido com a melhoria da qualidade dos serviços, implementou procedimento minucioso de gestão por desempenho. No contexto do planejamento estratégico - com o qual os funcionários estavam familiarizados e com descrições detalhadas das atribuições de cada cargo, os objetivos eram estabelecidos anualmente, com a participação de cada empregado. Uma reunião de avaliação anual, com pelo menos duas horas de duração, centrava-se no relatório preliminar do supervisor sobre o desempenho do servidor. $O$ fato de a discussão muitas vezes ser acalorada mostrava que o assunto era sério. A ênfase estava em melhorar o desempenho por meio do elogio e do incentivo e em tratar o desempenho insatisfatório inicialmente com aconselhamento e, por fim, com a 
demissão: a ZESCO, diferente de muitas agências públicas, tinha poder efetivo para contratar e para demitir.

Em outro extremo está o caso do Ministério da Saúde da Guatemala. No final dos anos 1990, o ministério não dispunha de qualquer sistema formal de gestão por desempenho. Até mesmo os relatórios mensais de prestação de serviços (por ex., cobertura de imunizações) e visitas de supervisão ao pessoal de campo muitas vezes não aconteciam, em parte devido à falta de recursos. Da mesma forma, até o final dos anos 1990, o único hospital para encaminhamento de doentes mentais dependia de um sistema de "relatórios anuais confidenciais", pelo qual os relatórios eram redigidos pelos gerentes de linha, normalmente sem qualquer tipo de comunicação com os servidores e encaminhados a algum órgão central, onde teoricamente eram utilizados para decisões sobre promoções. Conseqüentemente, não havia qualquer cultura de desempenho no hospital; pelo contrário: os funcionários muitas vezes não se encontravam em seus postos.

Chama a atenção o fato de que a Zesco não vinculava a gestão por desempenho a decisões sobre salários. $\mathrm{O}$ estabelecimento de tal vínculo era apoiado por alguns, mas é extremamente difícil fazer funcionar um sistema de salários vinculados a desempenho. A Malásia possivelmente foi além de qualquer outro país em desenvolvimento, tendo introduzido um sistema de gratificações anuais baseadas no desempenho, no início dos anos 1990. No início do novo século, contudo, decidiu voltar atrás, parcialmente substituindo um sistema de avaliações baseadas em cursos de treinamento pela avaliação do gerente. Isso ocorreu em resposta às queixas sobre avaliações tendenciosas de alguns gerentes, muitas vezes incluindo componente étnico, prestadas pelos sindicatos de servidores públicos ao longo de um período de dez anos.

Também há provas de pelo menos um país industrializado de que salários associados ao desempenho podem prejudicar o desempenho e a motivação, ao invés de melhorá-los (MARsDen; Richardson, 1994). No funcionalismo público de carreira, porém, há menos dificuldade em vincular a gestão por desempenho à promoção, utilizando mecanismos de que muitos países sempre dispuseram, mesmo que esse vínculo, na prática, fosse tênue.

Assim como em outras práticas de GRH, os governos precisam adaptar os modelos de "boas práticas" que se encontram nos manuais aos fatores contextuais. Um deles é a boa-vontade dos políticos de deixar que os gerentes façam o trabalho e tomem suas próprias decisões de recrutamento e demissão. Um segundo fator contextual é a reação dos sindicatos do setor público. Tentar impor um sistema de gestão por desempenho aos servidores pode ser contraproducente. Um dos motivos pelos quais a gestão por desempenho estava à beira da morte no hospital universitário de Zâmbia foi que o governo - ameaçado em 1997 por uma greve nacional dos sindicatos de serviços de saúde - retomou o poder de contratar e demitir que a Lei da Saúde, de 1995, havia dado aos hospitais. Nas Ilhas Maurício, os sindicatos questionavam o elemento salarial vinculado ao desempenho do novo esquema proposto ao final dos anos 1980, razão pela qual, dez anos depois, o país ainda não contava com um procedimento efetivo de gestão por desempenho. 
Redimensionamento de estruturas: colocando as questões de recrutamento nos trilhos novamente

Este trabalho oferece uma agenda positiva para a GRH no setor público. Os governos precisam, todavia, enfrentar o fato de que, de tempos em tempos, eles necessitarão reduzir seus gastos com pessoal. Mesmo reconhecendo que a redução de gastos de forma alguma equivale a demitir pessoal, conforme explicado mais adiante, a necessidade de reduzir gastos nem sempre é bem vista. Os governos - como foi o caso da República Unida da Tanzânia descobriram que pode haver mais espaço para a redução de déficits governamentais pela melhora na arrecadação tributária do que pela demissão de pessoal (MAmadou, 1996). Nesse sentido, o redimensionamento (rightsizing) assemelha-se a outras áreas de atividade, nas quais mudanças táticas podem se fazer necessárias para atingir resultados.

Há três motivos pelos quais o encolhimento é provavelmente uma característica inevitável no cenário governamental. Primeiro: muitas das atividades econômicas das quais os governos obtêm suas receitas seguem um ciclo de "boom" e "quebra", passando do crescimento à estagnação ou até mesmo à recessão. Em segundo lugar, os governos, especialmente em países pobres, são afetados por choques externos, tais como o aumento do custo do petróleo ou uma má colheita. No Marrocos, onde o PIB tende a acompanhar os níveis pluviométricos, o falecido Rei Hassan certa vez comentou que "se tiver que escolher entre um relatório da inteligência e uma previsão de tempo, colocarei o relatório da inteligência de lado" ". Em terceiro lugar, novas tecnologias tornam possível reduzir o número de pessoas necessárias para a realização de tarefas padronizadas, tais como o envio de formulários para cobrança de impostos. A clássica imagem dos anos 1970 do fotógrafo indiano Raghubir Singh, do Prédio de Escritores de Calcutá, o coração burocrático do governo de Bengal Ocidental, com suas fileiras cerradas de burocratas trabalhando sob pilhas e pilhas de papéis amarelados, não mais representa a administração pública, nem de países industrializados, nem de países em desenvolvimento.

\section{Uma abordagem estratégica ao redimensionamento}

E nos casos em que um governo julgar que rightsizing significa reduzir o número de servidores, como lidar com isso? Há três princípios a serem mantidos em mente. O redimensionamento efetivo:

- será estratégico, ou seja, partirá de um ponto de vista estratégico sobre para onde o governo ou um ministério está indo e uma percepção das implicações da estratégia para o emprego dos servidores;

- gerará economias reais, não meramente uma redução bruta no número de servidores; e

- minimizará o sofrimento dos servidores.

Apesar da impressão de que rightsiz̨ing significa concentrar-se exclusivamente na última linha das demonstrações financeiras (algo do qual ministros da Fazenda e certos organismos doadores têm sido ocasionalmente culpados) e é um aspecto que também se aplica ao modelo estratégico delineado neste artigo. Chegou-se a uma espécie de consenso de que virar uma organização de ponta cabeça é um processo de dois estágios, no qual a ação emergencial para estancar o declínio leva ao planejamento estratégico para o futuro, algo denominado de "estratégia de recuperação". 
Rightsizing é um processo que começa com uma estratégia de desenvolvimento global e um plano de GRH do governo ou do ministério individual. Uma revisão da gestão é realizada dentro daquele contexto estratégico e utilizada para gerar, quando apropriado, um plano de re-perfilamento, que inclua medidas para minimizar o sofrimento dos servidores, se necessário (a expressão "quando apropriado" significa que uma revisão não necessariamente leva a cortes de pessoal). O plano de aposentadoria voluntária, introduzido pelos bancos estatais da Índia entre novembro de 2000 e março de 2001, é um exemplo de uma experiência bem-sucedida de rightsizing (Quadro 3).

Paralelamente, nos processos de rightsizing, os governos precisam prestar atenção a medidas procedimentais específicas, pois representam uma preocupação constante. Nelas se incluem medidas que gerem sentimento de posse do programa e comprometimento com ele, bem como consultas e comunicação a servidores e seus representantes. O ritmo adequado do programa, que será ditado pelo cronograma do plano de ação estratégica, é outra questão. Assim que o marco estratégico tiver sido implantado, o próximo passo é tentar evitar cortes bruscos de emprego, utilizando as seguintes medidas:

- remover os fantasmas. A Uganda pensou que sua meta inicial de reduzir 34 mil empregos era dura, até descobrir nada menos que 42 mil funcionários fantasmas em seus registros (por exemplo, nomes fictícios incluídos na folha de pagamento, permitindo que terceiros pudessem receber um salário) (Government Of UGANDA, 1994);

- fazer valer a idade de aposentadoria. A Uganda descobriu vários milhares de servidores que continuavam trabalhando após a idade oficial para aposentadoria;
- combinar interrupção das seleções e a redução natural do quadro;

- abolir cargos vagos;

- realizar previsões de recursos humanos, a fim de antecipar necessidade decrescente em algumas áreas ou capacidade decrescente de pagar por eles;

- buscar a "flexibilidade funcional" por meio de capacitação para desempenho de múltiplas tarefas. A Ford Motor Company do Reino Unido, por exemplo, atuou no sentido de reduzir o número de categorias funcionais distintas de 516, em 1986, para 45, em 1988;

- estabelecer um procedimento de realocação, de modo que os servidores registrados em um pool de realocação sejam considerados primeiro, antes de um cargo ser noticiado pelas vias normais. É importante evitar abusar de tais pools, utilizando-os como depósito de funcionários que não mais usufruem de simpatia política, tais como servidores mais antigos identificados com o partido que estava no poder anteriormente;

- organizar treinamentos para converter, por exemplo, um administrador supérfluo em um programador de computadores; e

- antecipar excessos de pessoal por meio da implementação de procedimentos que permitam ao governo lidar com este problema sistematicamente. Tais procedimentos requerem algum tempo até se desenvolverem, especialmente quando é necessário consultar sindicatos, os quais deveriam fazer parte das práticas cotidianas de GRH. Em uma autoridade governamental local do Reino Unido, o acordo de demissão por excesso ou extinção de quadros, estabelecido já em 1977, permitiu à autoridade reduzir cargos ao longo de um período de vários anos, sem impor demissões compulsórias.

Se depois de tudo um governo ainda achar que necessita reduzir empregos, deve 


\section{Quadro 3: Um plano de aposentadoria voluntária - Índia}

Os bancos estatais da Índia eram geralmente considerados inchados em termos de quadro de pessoal antes da implementação do plano de aposentadoria voluntária (PAV), em 1999. Um estudo realizado pela Federação das Câmeras de Indústria e Comércio da Índia (Indian Chambers of Commerce and Industry - FICCI) revelou que este setor, em 1998-1999, contava com mais de 59 mil funcionários em excesso, se utilizado o parâmetro de $\$ 233.000$ em volume de negócios por funcionário (NPF). Se o NPF fosse aumentado para cerca de $\$ 291.000$, o número subia para mais de 177 mil funcionários em excesso, respondendo por $22 \%$ do total de funcionários em 16 bancos nacionalizados. Em termos de produtividade, o NPF e o lucro por funcionário (LPF) dos bancos públicos indianos estavam muito abaixo do NPF e LPF de bancos privados estrangeiros similares.

Apesar de criticado às vezes por suas conseqüências potencialmente negativas, incluindo a falta de sustentabilidade financeira, erosão de empregos e fuga de cérebros, os planos de aposentadoria precoce ainda são aceitos como estratégia eficaz de desenvolvimento de recursos humanos para reduzir o quadro de funcionários, melhorar a eficiência e a produtividade e equilibrar a composição entre faixas etárias e habilidades dos trabalhadores. Entre 15 de novembro de 2000 e 31 de março de 2001, a primeira rodada do PAV foi implementada em todos bancos estatais da Índia, à exceção de um. Todos os funcionários contratados com 15 anos de serviço ou com mais de 40 anos de idade ou, ainda, identificados como excedentes estavam qualificados para participar do plano de aposentadoria antecipada. Os funcionários que optaram pelo plano tinham direito a 60 dias de compensação para cada ano de serviço prestado ou o equivalente do salário para os anos remanescentes de serviço, dependendo de qual fosse menor. Aqueles que se qualificavam para o PAV, mas não estavam dispostos a optar pela aposentadoria precoce, tinham a opção de uma licença de cinco anos. Para minimizar o ônus financeiro criado pelo plano, o governo da Índia permitiu aos bancos efetuarem os pagamentos em duas parcelas, com um mínimo de $50 \%$ do valor a ser pago à vista e o remanescente em até seis meses, em dinheiro ou em títulos. O governo incentivou os bancos a emitirem títulos e garantiu seu pagamento, incluindo os juros provisionados.

Em termos de redução do quadro e de custos, o objetivo mais amplo do plano foi dramaticamente atingido. Do total de 863.117 funcionários dos 26 bancos estatais que implementaram a iniciativa, 100.810 funcionários (11,7\%) aceitaram a oferta, de acordo com um estudo publicado no informativo da Associação de Bancos Indianos (IBA). Em 2000-2001, os custos com pessoal de todos os bancos estatais (incluindo o Corporation Bank, que não optou pelo PAV), era de INR 21.050 crore (cerca de US\$ 4,7 bilhões). Em 2001-2002, ele havia caído para INR 18.959 crore (cerca de $\$ 4,3$ bilhões). Além disso, acredita-se que o PAV tenha ajudado a equilibrar o perfil de habilidades vis-à-vis a composição de funcionários. A próxima fase do PAV deverá enfocar o perfil etário dos trabalhadores.

Incentivado pelo sucesso inicial do PAV em bancos estatais, o governo da Índia começou a introduzir um plano similar no serviço público em setembro de 2004. Servidores públicos mais antigos, para os quais faltavam de um a cinco anos até a aposentadoria, estavam qualificados para participar dele. Foram oferecidos pacotes financeiros especiais, consistindo de um pagamento em parcela única, além dos benefícios normais de aposentadoria. Espera-se que este novo plano racionalize a mão-de-obra do serviço público e ainda prepare o governo para os novos desafios do envelhecimento populacional, da globalização e da modernização tecnológica. 
considerar os seguintes passos, organizados em ordem de dificuldade política (McCourt, 2001):

- introduzir horários de trabalho parcial e flexíveis;

- nomear novos servidores por meio de contratos temporários;

- pôr fim a esquemas de admissão garantida. Alguns governos, como o de Benin, na África Ocidental, tinham um esquema de acesso automático ao serviço público para todos os graduados. Considerando o número crescente de graduados, essa política talvez não seja a mais adequada para a maioria dos países;

- suspender a progressão automática. Do mesmo modo, alguns países tinham um sistema de promoção automática, baseada em antigüidade que, além de ter implicações salariais, enfraquece o vínculo entre promoção e mérito;

- introduzir a demissão voluntária por excesso de quadros. Isso muitas vezes é bem-vindo entre os servidores e, às vezes, as cotas são alcançadas mais rapidamente do que o governo espera (como no caso do Reino Unido). Contudo, pode ser caro: em Gana, consumiu 2\% do total de gastos governamentais ao longo dos cinco primeiros anos da reforma;

- privatizar/terceirizar. Isso pode reduzir o número de funcionários, mas não necessariamente os gastos: um serviço terceirizado não necessariamente é menos oneroso, conforme discutido anteriormente neste documento;
- congelar os salários; e

- implementar a demissão compulsória por excesso de quadros.

Uma característica marcante da lista acima é que a demissão compulsória por excesso de quadros, apesar de sua imagem popular, é apenas o último item de uma longa lista e poderá nunca ser utilizado se o governo conseguir economizar o suficiente por outros meios. Por outro lado, se as demissões se fazem necessárias, o empregador responsável deverá estar atento para minimizar as dificuldades enfrentadas pelo servidor atingido (Quadro 4).

De modo geral, depois de consultar os sindicatos e outros em relação a seus planos, é aconselhável que o governo concentre seu auxílio no tamanho da indenização em parcela única a ser paga e da pensão que os servidores demitidos receberão: há provas de que as pessoas tomam decisões melhores sobre como usar tal pagamento do que o governo o faria em seu nome (STEPHEN, 1996). Aconselhamento e informação também são importantes para afastar concepções equivocadas e para preparar os servidores para a mudança. Esquemas de retreinamento, que ajudem os servidores demitidos a adquirir novas habilidades são desejáveis em teoria, mas podem ser dispendiosos, difíceis de administrar e pouco direcionados, de modo que poucos acabam sendo beneficiados em termos práticos. 


\section{Quadro 4: Redimensionando de forma certa - Uruguai}

O Uruguai é um Estado de bem-estar social cujos cidadãos gozam de um dos mais altos padrões de vida fora do mundo industrializado. O setor público do país enfrenta inúmeros desafios, inclusive o de um funcionalismo desproporcionalmente inchado. Visto que a Constituição dificulta em muito a demissão de um servidor público, a redução do funcionalismo havia se tornado proposta pouco contundente. Outro fator complicador era o fato de que servidores públicos eram muitas vezes contratados com base em conexões políticas, o que levava a uma constante criação de novos órgãos e divisões, não raras vezes sem muita consideração pelas implicações financeiras. Devido ao tamanho exagerado do serviço público, os salários dos profissionais também eram muito baixos, forçando muitos servidores qualificados a trabalhar somente poucas horas por dia na repartição pública e passar o resto do dia em um emprego no setor privado para complementar sua renda. De acordo com um levantamento governamental realizado em 1995, as pessoas apoiavam a reforma do serviço público, mas somente se ela não resultasse em demissões e conflitos sociais.

A estratégia de modernização do setor público, implementada pelo governo de Julio Maria Sanguinetti, em 1995, adotou uma abordagem em duas etapas que enfatizou os incentivos e a participação voluntária no lugar de cortes nos empregos. O governo convidou os órgãos da administração central que levariam a cabo essa estratégia para definir as competências-chave necessárias e identificar as funções que poderiam ser eliminadas, seja transferindo-as para órgãos mais qualificados ou até mesmo terceirizando-as para empresas privadas. Se o plano de reestruturação do órgão fosse aprovado pelo Comitê Executivo de Reforma do Estado (criado a partir de um empréstimo de US\$115 milhões do Banco Inter-Americano de Desenvolvimento), ele era recompensado: passava a ter acesso a fundos especiais para cobrir os custos de indenizações, aposentadorias antecipadas ou transferências de quadros em excesso. Tais fundos também incluíam apoio técnico, treinamento empresarial e pequenos empréstimos para servidores públicos que optassem por iniciar seu próprio negócio. A cada órgão era permitido manter as economias geradas pela reestruturação, o que poderia ser utilizado para aumentar os salários dos funcionários remanescentes, investir em treinamento e equipamentos, bem como pagar gratificações baseadas no desempenho.

Os resultados desta abordagem foram espetaculares. Dos 108 órgãos executores que participaram do programa, 82 (representando cerca de 80 mil servidores públicos) reestruturaram suas operações com sucesso. Foi identificado um total de 9.221 cargos em excesso durante o exercício de reestruturação e mais de um terço dos servidores afetados receberam treinamento e auxílio para encontrar emprego no setor privado. Em 2002, um serviço público mais enxuto já estava economizando US $\$ 56$ milhões ao ano em dinheiro dos contribuintes; US $\$ 25$ milhões destinavam-se ao tesouro nacional, enquanto o resto era devolvido aos órgãos reestruturados para financiar os diversos programas de incentivo. O exercício completo de downsizing levou menos de três anos para ser implementado e, ao final do processo, o número de órgãos públicos havia sido reduzido em $46 \%$. A realização mais marcante foi que, durante esta fase, não ocorreu nem uma única greve ou ação trabalhista. Um fator fundamental para o sucesso do programa foi o envolvimento e o pleno apoio dos chefes dos órgãos, que viram neste exercício uma oportunidade para recrutar pessoal altamente qualificado e conceder aumento salarial aos servidores que o mereciam e que, caso contrário, estariam tentados a ir para a iniciativa privada. O programa também contava com credibilidade política, pois estava embutido no orçamento nacional, 
assegurando ao governo o tempo necessário para implementar as reformas - do contrário, um tempo precioso seria perdido em disputas políticas para gerar os recursos financeiros necessários.

Após o sucesso da primeira fase da reforma, o governo está iniciando uma segunda fase, que irá enfocar a melhoria do desempenho efetivo do serviço público. Todos os órgãos públicos, por exemplo, serão solicitados a definir seus produtos e serviços cuidadosamente, determinar indicadores e atingir metas de desempenho específicas. Os recursos públicos do próximo orçamento serão alocados com base no desempenho organizacional.

\section{Notas}

* Este texto constitui o capítulo 5 do relatório "Unlocking the Human Potential for Public Sector Performance - World Public Sector Report 2005”, publicado originalmente pela ONU (Divisão de Administração Pública e Gestão do Desenvolvimento/Departamento de Assuntos Econômicos e Sociais), em inglês, com o título "Managing people as a strategic resource". Tradução de Cristiane Feitosa e Anja Kamp e revisão técnica de Claudia Asazu e Larissa Mamed Hori.

${ }^{1}$ Disponível em <www.unodc.org/pdf/iaol/un_competencies.pdf>.

${ }^{2}$ Extraído de CAPPON, Lester J. (ed.). The Adams-Jefferson Letters: the complete correspondence between Thomas Jefferson and Abigail and John Adams. Chapel Hill: University of North Carolina Press, 1959. Disponível em http://press-pubs.uchicago.edu/founders/.

${ }^{3}$ Extraído de Kiragu, Kithinji. Pay reform: a critical and complex Public Service issue. Pricewaterhouse Coopers, 2004. Disponível em: www.pwcglobal.com/gx/eng/about/ind/gov/ ifi/pdf/public_service_pay_reform.pdf

${ }^{4}$ Extraído de Latham, Gary; WeXLey, Ken. Increasing productivity through performance appraisal. New York: Addison-Wesley, 1993.

${ }^{5}$ Extraído de Pennelu, Richard. Morocco since 1830: a history. London: Hurst Pennell, 2000, p. 324

\section{Referências bibliográficas}

Agenor, Pierre Richard; El Aynaoui, Karim. Labor Market Policies and unemployment in Morocco: a quantitative analysis. Washington, D.C.: World Bank, 2003.

Anderson, Jim, Reid, Gary, Ryterman, Randi. Understanding public sector performance in transition countries - an empirical contribution. Washington, D.C.: World Bank. Disponível em: http://www.worldbank.org/wbi/governance/govdonors/pdf/reid.pdf., 2003. 
Centre for Management and Organisation Development. A Guide to Competency Development in the Civil Service. Disponível em: http://www.finance.gov.ie/cstc/ cstdcresources/cmod_report.pdf, 2003.

CORKery, Joan; LAND, Antony. Civil service reform in the context of structural adjustment. a triangular relationship. Policy Management Brief, n.7. Maastricht: European Centre for Development Policy Management, 1997.

Council Of Europe. Civil Service Reform in Europe. Doc. 9711.Committee on Economic Affairs and Development. Parliamentary Assembly. disponível em: http:/ / assembly.coe.int/ Documents/WorkingDocs/doc03/EDOC9711.htm, 2003.

DiA, Mamadou. Africa's management in the 1990s and beyond: reconciling indigenous and transplanted institutions. Washington, D.C.: World Bank, 1996.

GarnetT, Harry; Stevens, Mike. Establishment control and pay determination. World Bank. Disponível em: http://www1.worldbank.org/publicsector/civilservice/ establishment.htm., 2000.

Government of CAnAda. Organization for Economic Co-operation and Development, 2001. Issues and Development in Public Management. Canada: 2001. disponível em: http:// www.oecd.org/dataoecd/39/25/1923850.pdf, 2001.

Governmet of UGanda. Management of change: context, vision, objectives, strategy and plan. Kampala: Ministry of Public Service, 1994.

Henderson, Jeffrey. [et al]. Bureaucratic effects: 'Weberian' State structures and poverty reduction. Working paper $\mathrm{n}^{\circ}$ 31, Chronic Poverty Research Center. Disponível em: http:// www.chornicpoverty.org/cpreports2.htm, 2003.

Hood, Christopher; Scott, Colin; Jones, George; Travers, Tony. Regulation Inside Government: waste watchers, quality police and sleaze-busters. Oxford: Oxford University Press, 1999.

JoHSON, Gerry; SCHOLES, Kevan. Exploring corporate strategy: text and cases. London: Financial Times/Prentice Hall, 2002.

Keuleers, Patrick. Key issues for consideration when assisting civil service personnel management reforms in developing countries. Subregional Resource facility for the Pacific, Northewast and Southeast Asia. Bangkok: United Nations Development Programme, 2004.

KIRAgu, Kithinji. Pay reform a critical and complexpublic service issue. Pricewaterhouse Coopers. Disponível em : http://www.pwcglobal.com/gx/eng/about/ind/gov/ifi/pdf/ public_service_pay_reform.pdf., 2004.

Kiragu, Kithinji, Mukandala, Rwekaza Public Service Pay Reform (Draft Reform). Washington, D.C.: World Bank. Disponível em: http://www.1.worldbank.org/ publicsector/civilservice/Mayseminar/PayReformStudy.pdf., 2003.

. Pay reform and policies report. Development Assistance Committee. Paris:

Organization for Economic Co-operation and Development., 2004.

LATHAM, Gary; WeXLeY, Ken. Increasing productivity through performance appraisal. New York: Addison-Wesley, 1993. 
Marsden, David; Richardson, Ray. Performing for pay? The effects pf 'merit pay' on motivation in a public service. British Journal of Industrial Relations. Vol.32, 2 edição, p. 243-261, 1994.

Martinez, Javier; Martineau, Tim. Measuring and monitoring staff performance in reforming health systems. Projeto de Pesquisa PN10. Disponível em: http://www.liv.ac.uk/lstm/ hsr/hsrpn10.html, 2000.

McCourT, Willy. Towards a strategic model of employment reform: explaining and remedying experience to date. International Journal of Human Resource Management. Vol. 12, 1ª edição, pp.56-75, 2001.

Nunberg, Barbara. Experience with civil service pay and employment reform: an overview. Rehabilitating Government: pay and employment reform in Africa. David L. Lindauer, Barbara Nunberg (eds). Washington, D.C.: World Bank, pp. 119-159.

Organisation for Economic Co-operation and Development. In: Barbara Nunberg (2000). Ready for Europe: Public Administration Reform and European Union Accession in Central and Eastern Europe. World Bank Technical Paper n ${ }^{\circ}$ 466. Washington, D.C.: World Bank, 1995.

Pennell, Richard. Morocco since 1830: a history. London :Hurst Pennell, p. 324, 2000. Polidano, Charles.; Manning, Rick. Redrawing in lines: service commissions and the delegation of personnel management. Managing the public service: strategies for improvement. $\mathrm{n}^{\circ}$ 2. London: Commonwealth Secretariat, 1996.

Rauch, James E.; Evans, Peter. Bureaucratic structure and performance in less developed countries. Journal of Public Economics. Vol. 75, n 1, Jan., pp.49-71, 2000.

- Bureaucracy and growth: a cross-national analysis of the effects of 'Weberian' state structures on economic growth. American Sociological Review. Vol.64, $\mathrm{n}^{\circ} 5$, Oct., p. 748-765, 1999.

ReID, Gary J.; SCOTT, Graham. Public sector human resource management: experiences in Latin America and the Caribbean and strategies for reform. Washington, D.C.:World Bank, 1994.

STELLA, Peter. Tax Farming - a radical solution for developing country tax problems? Washington, D.C.: trabalho no 92/70. International Monetary Fund, 1992.

Sulemane, José A.; Kayizzi-Mugerwa, Steve. The Mozambican civil service: incentives, reforms and performance. República de Moçambique: Trabalho no 25, Gabinete de Estudos do Ministério do Plano e Finanças. Disponível em: http:/ /www.wider.unu.edu/publications/ dps/dp2001-85-dp25.pdf, 2001.

TAYLOR, Harry. Public sector personnel management in three African countries: current problems and possibilities. Public Administration and Development. Vol. 12, p. 193-207, 1992.

Ulrich, Dave. A new mandate for human resource. Harvard Business Review. Vol. 76, $1^{\text {a }}$ edição Jan./ Fev., p. 124-135, 1998.

United Nations. Innovation and quality in government of the $21^{\text {st }}$ century. Fifth Global Forum on Reinventing Government: capacity development workshops. Department of Economic and Social Affairs. ST/ESA/PAD/SER.E/84. 2005. 
World BAnK. Cambodia: enhancing service delivery through improved resource allocation and institutional reform. Integrated Fiduciary Assessment and Public Expenditure Review. Washington, D.C.: World Bank, 2003.

. Checklist on law drafting and regulatory management in Central and Western Europe. Sigma papers: n 15, 1997.

. Peru - Restoring fiscal discipline for poverty reduction. Public Expenditure Review, Washington, D.C.: World Bank, 2002.

Republic of Yemen: comprehensive development review. Phase I. Washington, D.C.: World Bank, 2000.

Younger, Stephen. Labour market consequence of retrenchment for civil servants in Ghana. Economic reform and the poor in Africa. David E. Sahn (ed), Oxford: Claredon Press, p. 185-202, 1996. 


\section{Resumo - Resumen - Abstract}

\section{A gestão de pessoas como um recurso estratégico \\ ONU/Departamento de Assuntos Econômicos e Sociais}

O texto examina as estratégias e os sistemas que devem ser considerados para se alcançar a melhor gestão de recursos humanos no setor público. Inicialmente, baseado em três modelos tradicionais de administração pública, sugere uma abordagem holística para aumentar a efetividade da gestão. Em seguida, defende a idéia de um órgão "guardião" central, que considere o princípio do mérito e que divida com os órgãos de linha a responsabilidade sobre a GRH. Mostra, ainda, a importância de institucionalizar os valores da imparcialidade, do profissionalismo e da responsividade. Ao tratar da profissionalização da GRH, ressalta a necessidade de uma política que defina como a gestão de pessoas contribuirá para o alcance de objetivos governamentais. Para isso, propõe a aplicação de um modelo integrado baseado em competências e o desenvolvimento de uma política salarial que permita a atração e retenção de talentos no setor público. Ao final, o texto apresenta os prós e contras da gestão por desempenho, bem como os desafios de um redimensionamento organizacional no serviço público.

Palavras-chave: gestão de recursos humanos, mérito, política salarial, serviço público.

\section{La gestión de personas como un recurso estrategico ONU/DESA}

El texto analiza las estrategias y los métodos que los gobiernos deben considerar a fin de alcanzar la mejor gestión de recursos humanos en el sector público. La primera parte, basado en tres modelos de administración pública, propone un abordaje holístico para aumentar la efectividad de la gestión. A continuación, defiende la construcción de una agencia central que considere el principio del mérito y que divida con las agencias de ejecución la responsabilidad sobre la GRH. Además, muestra la importancia de institucionalizarse los valores de la imparcialidad, profesionalismo y responsividad. Al tratar de la profesionalización de la GRH, el texto resalta la necesitad de una política que defina como la gestión de personas contribuirá con el alcance de objetivos gubernamentales. El texto propone también la aplicación de un modelo basado en competencias y el desarrollo de una política salarial que permita la atracción y retención de talentos en sector público. En el final, el texto presenta los pros y los contras de una gestión por desempeño y también los desafíos de un redimensionamiento organizacional en el servicio público.

Palabras-clave: gestión de recursos humanos, mérito, política salarial, servicio público.

\section{Managing people as a strategic resource \\ ONU/DESA}

The text presents the strategies and systems that should be considered to obtain the best human resource management in the public sector. The first part of the text is based on three traditional models of public administration. The text then advocates the idea of a central "guardian" agency, which considers the principle of merit and which shares the HRM responsibilities. It also shows that it is important to institutionalize the values of impartiality, professionalism and responsiveness. Discussing the HRM professionalism, the text points out that governments need to develop a policy that defines how staff management will help the achievement of government goals. Thus, it suggests the use of an integrated competence-based model and the development of a pay-salary policy that allows governments to attract and retain talents in the public sector. It then finalizes presenting the pros and cons of a performance management, as well as the challenges of implementing rightsizing in the public sector.

Key words: human resource management, merit, pay-salary policy, public service. 